\title{
Ground-shaking scenarios and urban risk evaluation of Barcelona using the Risk-UE capacity spectrum based method
}

\section{Bulletin of Earthquake}

\section{Engineering}

Official Publication of the European Association for Earthquake Engineering

ISSN 1570-761X

Volume 9

Number 2

Bull Earthquake Eng (2011)

9:441-466

DOI $10.1007 /$

s10518-010-9222-6
April 2011, volume 9, No. 2

ISSN 1570-761X

DULLETIN OF
EAEEENGINAREARE
EARING

Official Publication of the European Association for Earthquake Engineering

EDITOR

Atilla Ansal

EDITORIAL BOARD

Nicholas N. Ambraseys Martin Koller

Nuray Aydınoğlu Alberto Marcellini

Pierre-Yves Bard

Philippe Bisch

Franco Braga

Carlos Sousa Oliveira

Roberto Paolucci

Mauro Dolce

John Douglas

Peter Fajfar

Michael Fardis

Rainer Flesch

Mihail Garevski

George Gazetas

Andreas Kappo

Faruk Karadoğan

Alain Pecke

Rui Pinho

Kyriazis Pitil

Erdal \$afak

Ragnar Sigbjörnsson

Dario Slejko

Robin Spence

Costas Syrmakezis

Miha Tomaževič 

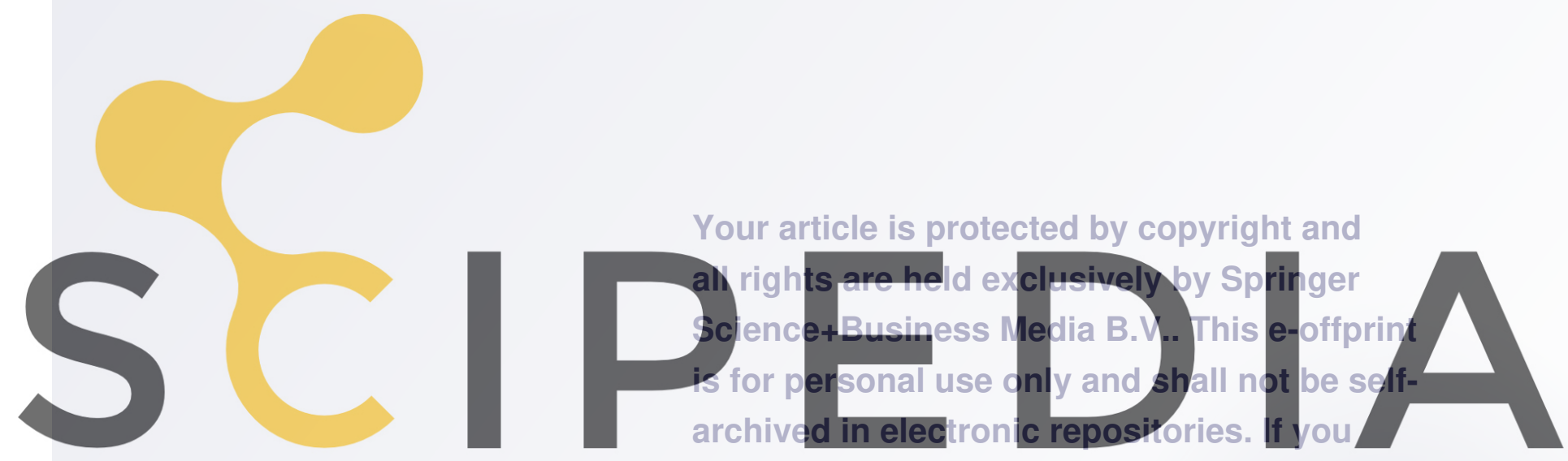

wish to self-archive your work, please use the

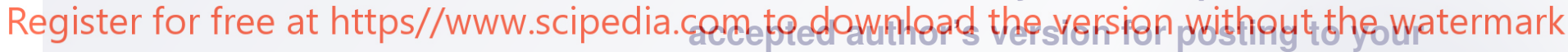

own website or your institution's repository.

You may further deposit the accepted author's version on a funder's repository at a funder's request, provided it is not made publicly available until 12 months after publication. 


\title{
Ground-shaking scenarios and urban risk evaluation of Barcelona using the Risk-UE capacity spectrum based method
}

\author{
J. Irizarry • N. Lantada - L. G. Pujades • \\ A. H. Barbat • X. Goula - T. Susagna - A. Roca
}

Received: 13 March 2009 / Accepted: 24 October 2010 / Published online: 12 November 2010

(C) Springer Science+Business Media B.V. 2010

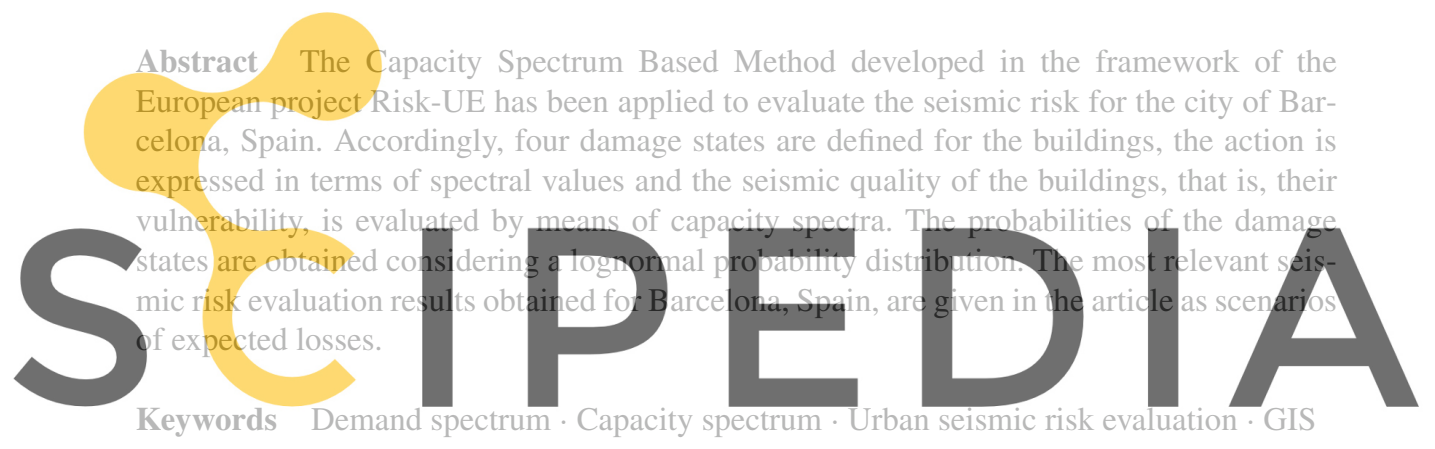

Register for free at https//www.scipedia.com to download the version without the watermark

\section{Introduction}

The Risk-UE project (Mouroux and Lebrun 2006a,b) established a methodology for evaluating urban risk which is based on the Capacity Spectrum Method (Freeman 1978, 1998; HAZUS 1999). Such methodology requires that the vulnerability of the building stock is defined in terms of a capacity spectrum and that the seismic hazard is defined in terms of spectral values. Then, it permits evaluating the expected seismic performance of structures by

J. Irizarry $\cdot$ X. Goula $\cdot$ T. Susagna $\cdot$ A. Roca

Institut Geològic de Catalunya , C/Balmes, 209-211, 08006 Barcelona, Spain

e-mail: jirizarry@igc.cat

\section{N. Lantada $(\bowtie) \cdot$ L. G. Pujades}

Department of Geotechnical Engineering and Geosciences, Civil Engineering School, Technical University of Catalonia, C/Jordi Girona 1-3 Edificio D2, Campus Norte UPC, 08034 Barcelona, Spain e-mail: nieves.lantada@upc.edu

\section{A. H. Barbat}

Department of Structural Mechanics, Civil Engineering School, Technical University of Catalonia, C/Jordi Girona 1-3 Edificio C1, Campus Norte UPC, 08034 Barcelona, Spain

e-mail: alex.barbat@upc.edu 
comparing, in spectral coordinates, their seismic capacity with the seismic demand described by Acceleration-Displacement Response Spectra (ADRS) and adequately reduced in order to take into account the inelastic behaviour (Fajfar 2000, 2002).

These methodologies have been applied to the city of Barcelona, Spain, which was one of the seven pilot cities participating in the Risk-UE project. The seismicity affecting Barcelona, located in the Catalonia region, is moderate, as the tectonic deformations are weak when compared to other countries of the Mediterranean region. The seismic hazard assessment for urban areas developed within the Risk-UE project includes both deterministic and probabilistic approaches to obtain acceleration response spectra including soil effects (Faccioli 2006). Fragility curves and damage probability matrices (DPM) have been computed for the six more common structural types in the city, both from a deterministic and a probabilistic point of view. Next, a damage and loss estimation exercise, involving all the dwellings of the city, has been carried out using the derived DPM, the residential building stock inventory and the population database of Barcelona.

The main objective of this article focuses on the adaptation and application to Barcelona of the Capacity Spectrum Based Method (CSBM) as recommended within the framework of the Risk-UE project (Milutinovic and Trendafiloski 2003). Most of the city's building stock was constructed when no seismic codes were available. The combination of very old buildings constructed without seismic awareness and conscience and a highly populated and active city can be extremely risky under the effects of even moderate earthquake events. The most relevant seismic risk evaluation results obtained for the city of Barcelona using this methodology are finally shown in this article.
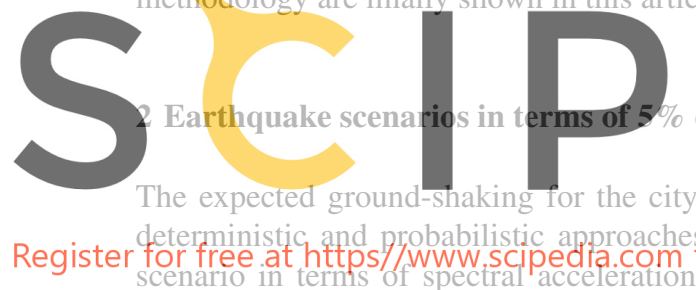

The expected ground-shaking for the city of Barcelona was obtained implementing both deterministic and probabilistic approaches (Faccioli 2006). The deterministic earthquake scer free at https/ www scipedia. com to download the version without the watermark ence earthquake that represents the actual maximum earthquake that has affected the site.

The probabilistic earthquake scenario was calculated using the CRISIS99 code (Ordaz et al. 1999) and the seismotectonic zonation and seismicity analysis previously performed by Secanell et al. (2004). The attenuation relationship from Ambraseys et al. (1996) was chosen within the Risk-UE project to be used for both approaches. This attenuation relationship is mostly based on European data, makes no distinction on the type of source mechanism of the earthquake data, uses a simplified soil classification and covers a wide range of distances and magnitudes. Ground-shaking results are expressed in the form of acceleration response spectra at $5 \%$ damped elastic response spectrum.

\subsection{Deterministic seismic scenarios}

The deterministic scenario in terms of spectral values was evaluated using two reference earthquakes selected from the catalogue of historical seismicity of the region (Susagna and Goula 1999) that affected the city of Barcelona.

The event with the highest epicentral intensity and the minimum distance to Barcelona is the one that occurred in 1448 in the Cardedeu area with an epicentral intensity of VIII (MSK) (Susagna and Goula 1999). It occurred at an epicentral distance of $15 \mathrm{~km}$ from the city and was assigned an approximate focal depth of $7 \mathrm{~km}$. The highest intensity ever felt in the city due to a distant event comes from the 1428 event in the Eastern Pyrenees region 


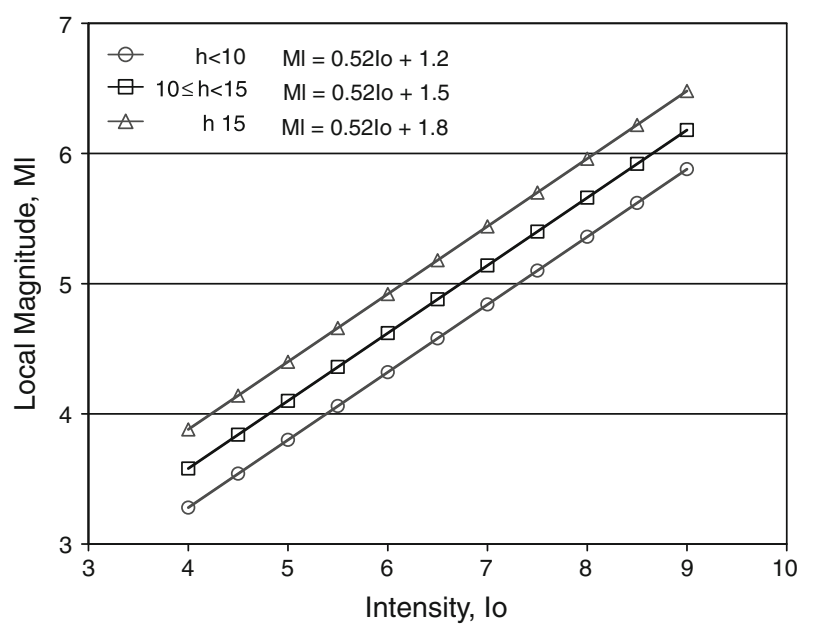

Fig. 1 Intensity-magnitude relationship used for the seismic hazard assessment

with an epicentral intensity of IX (MSK) (Susagna and Goula 1999). The 1428 earthquake had an approximate epicentral distance of $90 \mathrm{~km}$ from Barcelona city and it is associated to a focal depth of $10 \mathrm{~km}$. Both earthquakes caused damages in houses, churches and castles

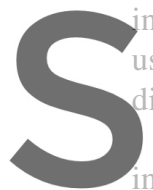
Barcelona. The con sed to develop the detert istant 1428 earthquak

To define the determ intensities had to be tra
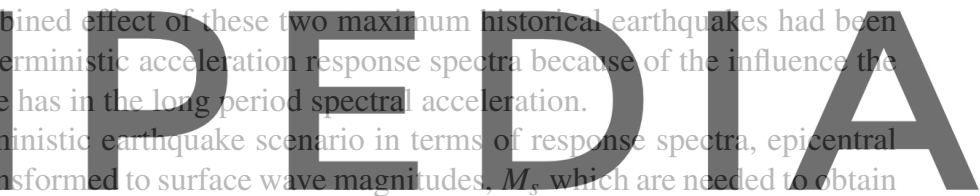

the corresponding acceleration response spectra by using the Ambraseys et al. (1996) atten-

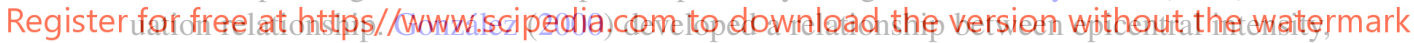

$I_{0}$, and local magnitude, $M_{l}$, based on data available for Catalonia, which was modified in this study to explain uncertainties by including the effect of the depth of the seismic source zone in which it was applied (Fig. 1).

In the lack of sufficient Catalonian data to develop a relationship between local and surface magnitude, and assuming that for Catalonia $M_{l}$ and $m_{b}$ are almost equal, the problem of the difference in magnitude scales was solved using the relationship developed by Dufumier (2002) using French data

$$
M_{S}=1.75 M_{b}-4.3
$$

With this relationship, local magnitudes were transformed into surface wave magnitudes so that the spectral acceleration values could be evaluated using the Ambraseys et al. (1996) attenuation relationship. Applying these two relationships and using a focal depth of $7 \mathrm{~km}$, a local magnitude, $M_{l}$, of 5.4 and a surface wave magnitude, $M_{s}$, of 5.1 are obtained for the 1448 earthquake near Barcelona with an epicentral intensity of VIII. The 1428 earthquake in the Pyrenees, with an epicentral intensity of IX and a focal depth of $10 \mathrm{~km}$, is assigned a local magnitude of 6.2 and a surface wave magnitude of 6.5.

Using the attenuation relationship of Ambraseys et al. (1996), the acceleration response spectra for rock were calculated for both earthquakes. The shorter distance earthquake controls the 5\% damped acceleration elastic response spectrum for high frequencies (up to $1 \mathrm{~Hz}$ ). The more distant earthquake controls the long period range. This increase of the energy in the 


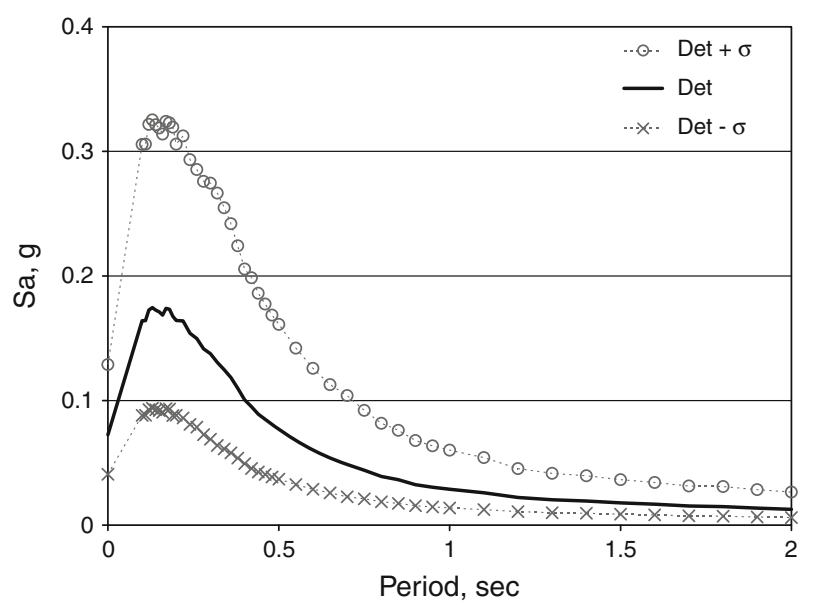

Fig. 2 Deterministic acceleration response spectrum $\pm \sigma$ for rock site condition in Barcelona

long period range is due, not only to the longer distance but also to the higher magnitude of the 1428 event. In fact, both earthquakes are independent and, strictly, the risk analysis should $\longrightarrow$ ind to choose the envelop the longer distance eart ormer response spectru would not be significant. In the final deterministic acceleration spectrum shown in Fig. 2, a lues. However, in this case, the contribution of
ry stightexcess in the long period range of the
at the differendes among the conplete analysis
enveiope of the spectrua of both earthquakes,

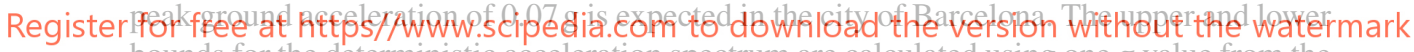
bounds for the deterministic acceleration spectrum are calculated using one $\sigma$ value from the Ambraseys et al. (1996) attenuation relationship.

\subsection{Probabilistic seismic hazard assessment}

The basis for the Probabilistic Seismic Hazard Assessment (PSHA) was established by Cornell (1968) with his proposal of an algorithm for the calculation of the seismic hazard that was later enhanced by others such as McGuire (1976). A probabilistic seismic hazard assessment takes into account the ground motions from the full range of earthquake magnitudes that can occur on each fault or source zone that can affect a site (Cornell 1968).

The first step for this zoned probabilistic seismic hazard assessment is the definition of the seismotectonic sources, which can be defined as points, lines or areas depending on the nature of the seismicity. The definition of the seismic sources is accomplished through the study of the spatial distribution of the seismicity and the geological, geophysical and seismic characteristics of the influence zone of the site. A seismic model must be defined for each seismic source describing the temporal occurrence of earthquakes in the zone as well as the frequency of occurrence of earthquakes according to its magnitude. Once the seismicity of the sources is characterized, the distribution of the parameter indicating the seismic hazard at the site must be obtained for each zone using an appropriate attenuation relationship. Finally, the seismic hazard for the site studied is defined as the exceedance probability of a certain level of the seismic hazard parameter as a result of the contribution of each one of the sources 
Fig. 3 Seismotectonic zonation of Catalonia and its influence area (Secanell et al. 2004)
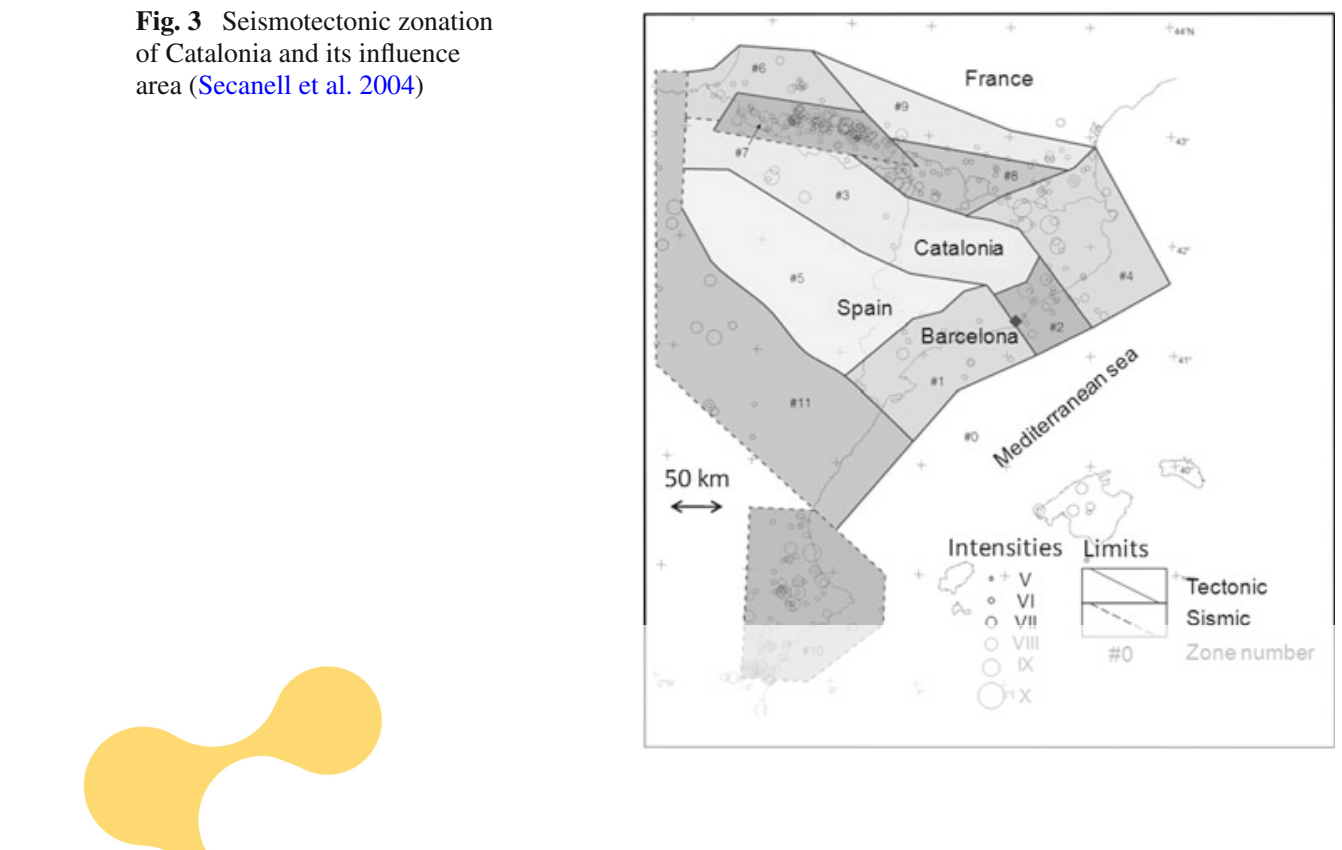

to the seismic hazard of the site. Several computational tools which implement Cornell's nethod are available. Because the locatid ately known, seismic he region. Secanell dt al. (2004) defined assuming that the heterogeneous nature of the continental crust in the northeast of the Tberian Peninsula could cause the distribution and different characteristics of the observed seismicity
Register for free at htto 5 , WWW.scipedia.com to download the version without the watermark

The macroseismic earthquake catalogue used by Secanell et al. (2004) contains a total of

876 earthquakes selected from an initial group of almost 2000 events. This catalogue includes events within Catalonia's influence area: the northeastern part of the Iberian Peninsula and the French Pyrenean Region. For major events, the catalogue was considered to be complete for a period up to 750 years.

The seismicity of the 11 zones of the seismic zonation was modelled using the truncated Gutenberg-Richter model (Goula and Godefroy 1985). The most actives zones affecting Catalonia are the central Pyrenees (zone 7) and zone 10 (situated outside Catalonia) (Secanell et al. 1998). The seismicity parameters in terms of intensity obtained by Secanell et al. (2004) were transformed using the intensity-magnitude relationship from González (2000) to obtain these parameters in terms of local magnitude, $M_{l}$ (Irizarry 2004). An example of this transformation for seismic source zone 2 is shown in Fig. 4.

The Risk-UE project selected the CRISIS 99-18 (Ordaz et al. 1999) computer code for evaluating the probabilistic seismic hazard. It is a flexible tool of analysis that can be used to evaluate seismic hazard in a various seismotectonic contexts using a probability model that considers the time occurrence process and distribution of earthquakes. CRISIS 99-18 allows the simultaneous hazard calculation for several hazard parameters and several spectral ordinates using different attenuation relationships.

The distance definition of the Ambraseys et al. (1996) attenuation relationship was adapted to be implemented in CRISIS 99-18 software. The Ambraseys et al. (1996) attenuation 

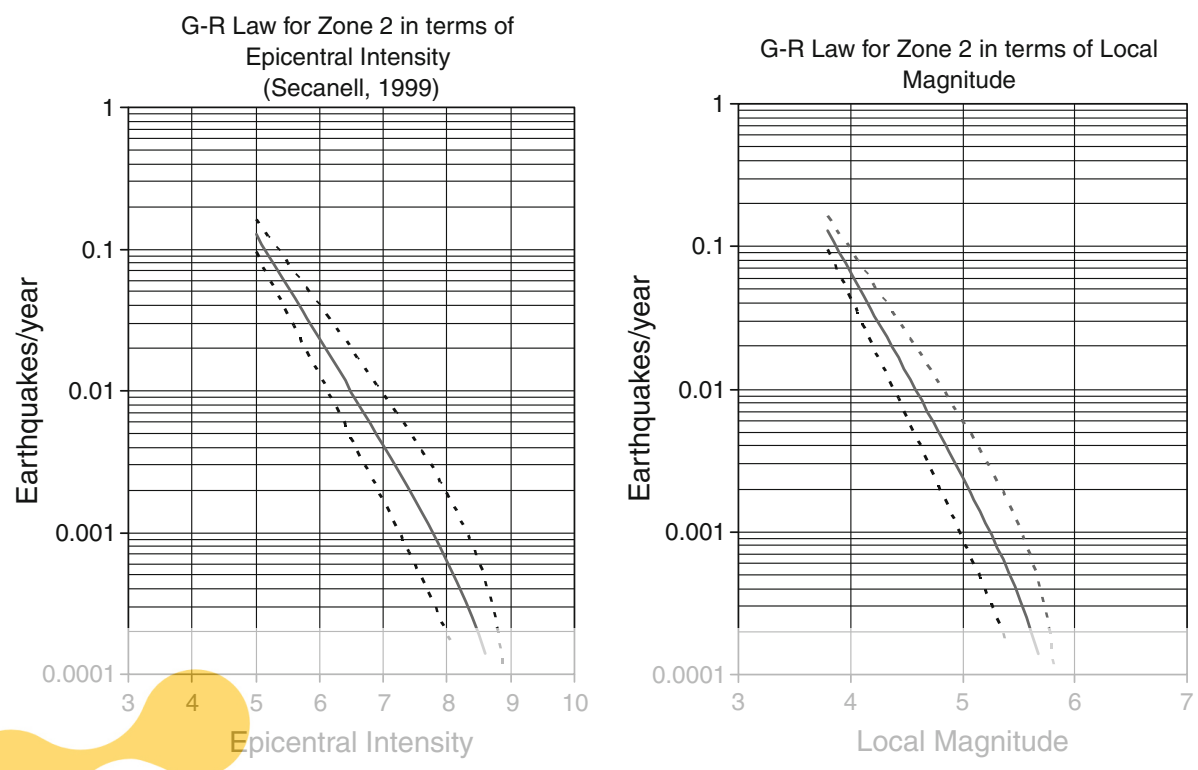

Fig. 4 Example of the transformation of the Guttenberg-Richter relationship from intensity to Ml for seismic source zone 2
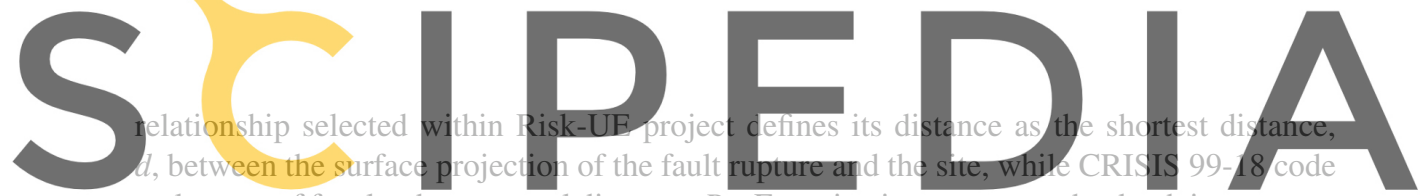

makes use of focal or hypocentral distance, $R_{h}$. For seismic zones were the depth is constant,

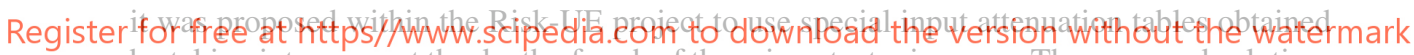

by taking into account the depth of each of the seismotectonic zones. The proposed solution, presented in detail in Faccioli (2006), is based on the Wells and Coppersmith (1994) correlation for subsurface ruptures. In addition, the Dufumier (2002) relationship was used to overcome the fact that seismicity parameters are defined in terms of local magnitudes, $M_{l}$, while the attenuation relationship is defined for surface wave magnitude, $M_{s}$.

Being Barcelona a relatively small city, the spectral values are expected to show small variation within the city. A total of 8 points were selected in order to compare their corresponding acceleration response spectra and study the variation of the response spectra in the city. For this reason, a single acceleration response spectrum was selected for the whole city of Barcelona (Irizarry 2004). Acceleration response spectra for a rock site condition associated to various return periods were obtained for Barcelona, whose acceleration response spectra for a rock site condition and associated to return periods of 100, 475, 1000 and 1500 years are shown in Fig. 5.

\subsection{Site soil amplification effects}

There are several ways to estimate site effects: characterizing them by using a soil-type classification, deriving them directly from observed records, taking ratios of horizontal to vertical components and modelling the ground as a medium of seismic wave propagation from the source to the site studied. Within the Risk-UE project, the recommended site effects evaluation is based on using a geotechnical zonation of the studied area and on calculating 


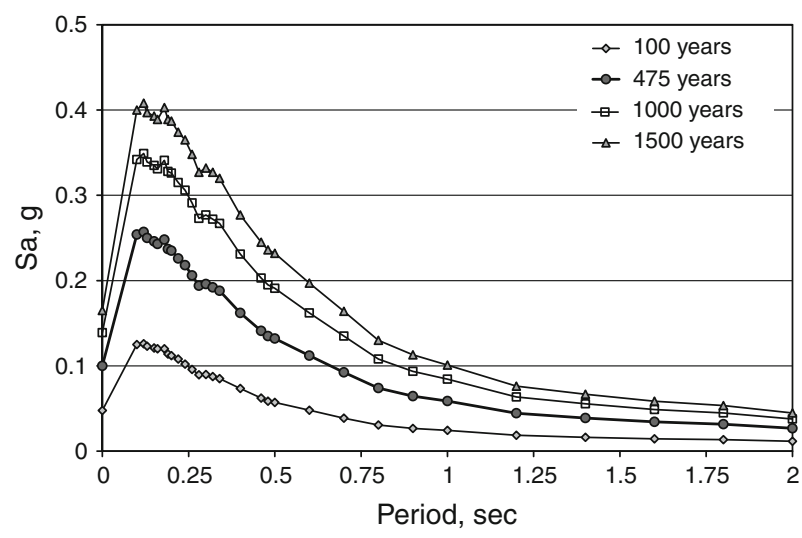

Fig. 5 Spectral acceleration response for rock sites at Barcelona for different return periods

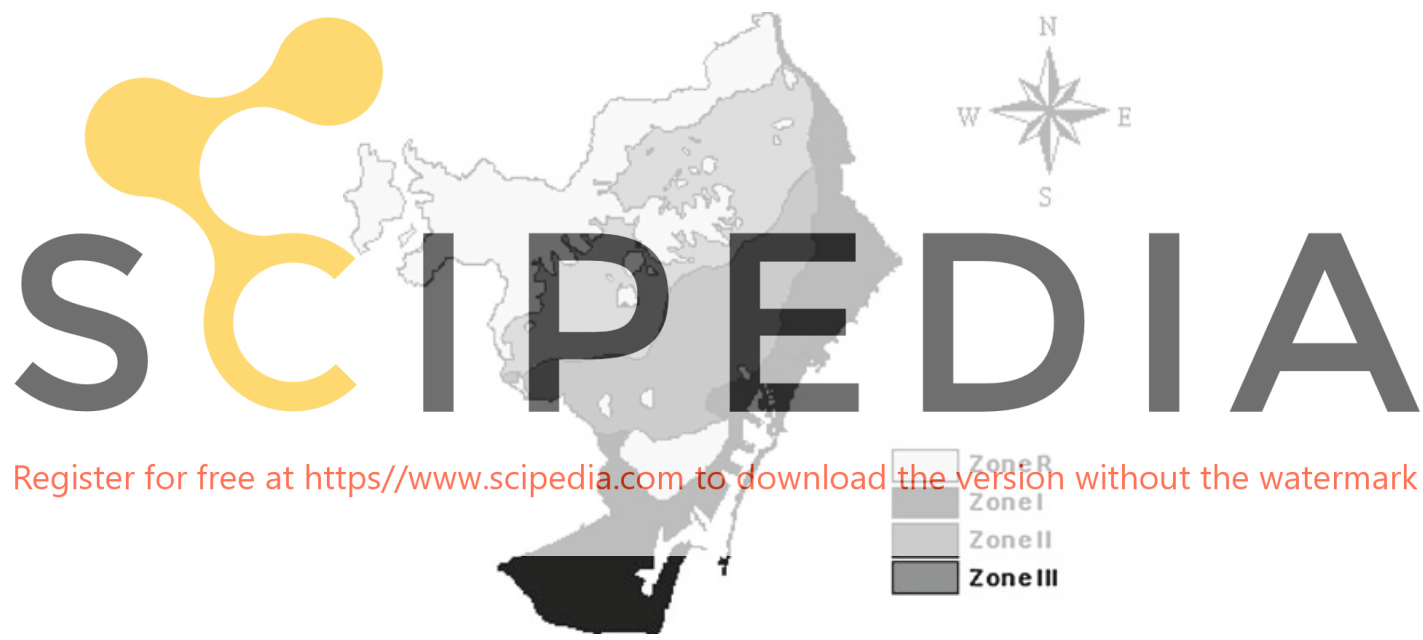

Fig. 6 Seismic zonation of Barcelona according to local effects (Cid et al. 2001)

the 1D linear equivalent response to obtain the values of amplification that can be expected at the studied site (Faccioli 2006).

For the city of Barcelona, the results from a previous seismic zonation were used to evaluate the site effects in terms of spectral amplification factors. Cid et al. (2001) published a seismic zonation for the city of Barcelona based on the simulation of local effects (Fig. 6). A 1D equivalent linear Shake method (Schnabel et al. 1972) was used by Cid et al. (2001) to compute complete transfer functions that allowed classifying zones with similar behavior. Data for this study consisted of a set of 70 columns with geotechnical information.

These zones correspond roughly to the four main geological units, i.e.: Zone I, Holocene deposits from the Llobregat and Besòs deltas; Zone II, Pleistocene formations with a Tertiary base with sufficient thickness to have an influence on the soil amplification; and Zone III, Pleistocene outcrops without the Tertiary base with sufficient thickness to have an influence on the response. Zone R corresponds to rock outcrops (Paleozoic and Tertiary). Each zone is 


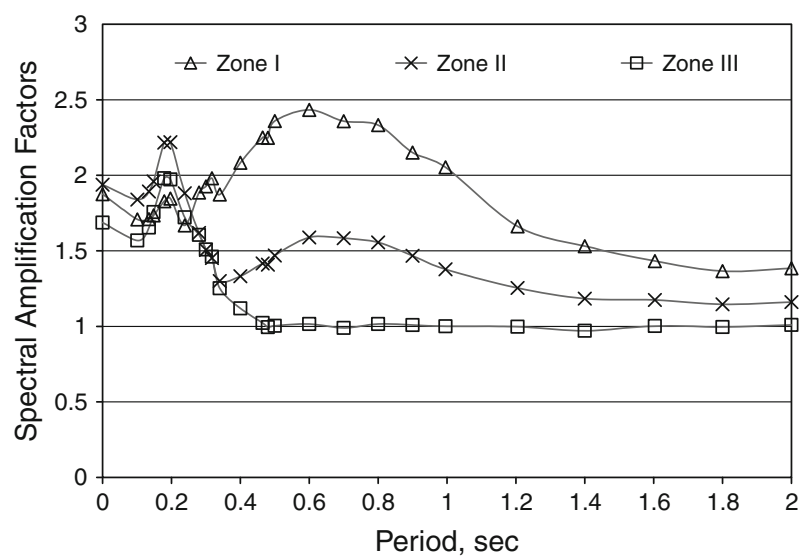

Fig. 7 Spectral amplification factors for all periods considered in the calculation

\section{characterized by an average normalized transfer function and by an amplification factor for} the peak ground acceleration level (PGA), relative to Zone R.

The first step in the calculation of the amplification factors for the spectral acceleration was finding a set of five real worldwide recorded acceleration time-histories having mean acceleration response spectra with a maximum of a $20 \%$ of difference from the target spectrum for rock associated to a return period of 475 years. These time histories were selected from the European stron

The Fourier transfor heir convolution with istories was obtained f
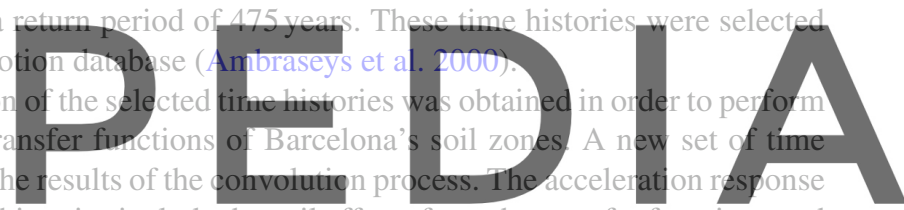

spectra from these new time histories include the soil effects from the transfer functions and

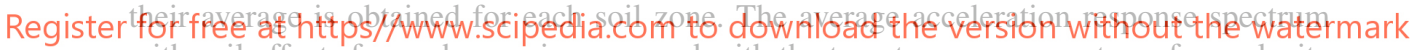
with soil effects for each zone is compared with the target response spectrum for rock site conditions to calculate spectral amplification factors for each soil zone.

This process was carried out using the Paleozoic basement of the city as reference site and the obtained spectral amplifications were higher than expected. Ambraseys et al. (1996) define the rock condition with a shear wave velocity greater than $750 \mathrm{~m} / \mathrm{s}$, so the attenuation relationship can be considered to be for a medium type of rock and not for a very hard rock with shear velocities in the order of $2000 \mathrm{~m} / \mathrm{s}$ as the Paleozoic basement of Barcelona. For this reason, the Tertiary outcrop of Montjuïc were preferred as a reference site because its shear wave velocity varies between 550 and $1500 \mathrm{~m} / \mathrm{s}$. Figure 7 shows the amplification factors for all the periods considered in the calculations.

\subsection{Deterministic and probabilistic acceleration response spectra with soil effects}

The spectral amplification factors were applied to the mean deterministic spectral acceleration values of Fig. 2. The deterministic acceleration response spectra with soil effects for the different soil zones within Barcelona are shown in Fig. 8. As mentioned before the higher amplifications are found in the short period range. The deterministic acceleration response spectra obtained represents lower spectral acceleration levels than the probabilistic acceleration response spectra for a return period of 475 years.

The probabilistic acceleration response spectra for the different soils within Barcelona are based on the probabilistic acceleration response spectrum for rock associated to a return 


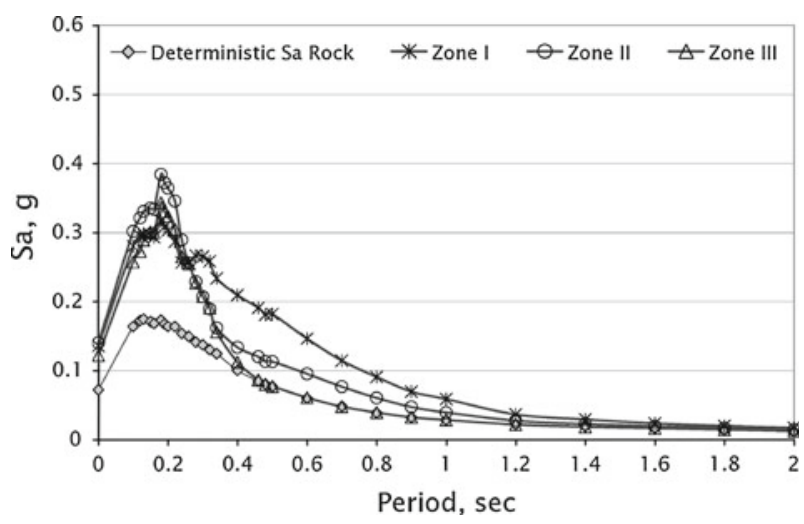

Fig. 8 Deterministic acceleration response spectra for the different soil zones of Barcelona

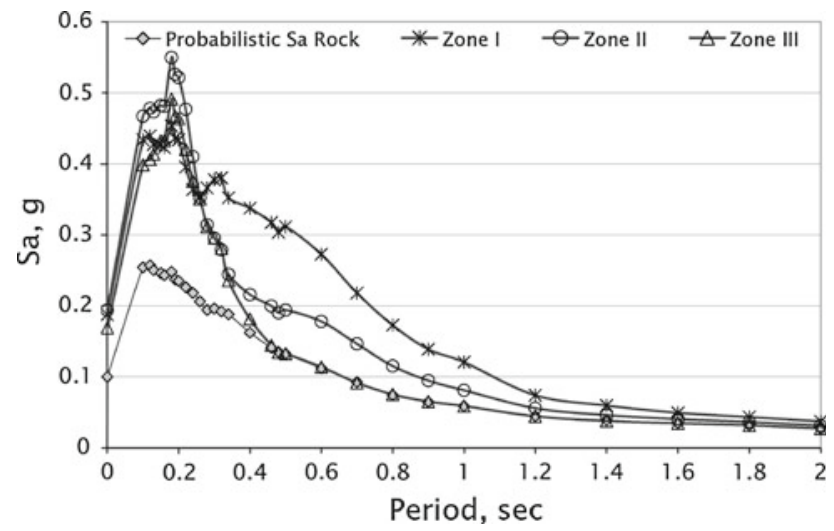

Fig. 9 Probabilistic acceleration response spectra with a return period of 475 years for the different soil zones of Barcelona

period of 475 years (Fig. 5). The spectral amplification factors were applied to the mean acceleration response spectrum to obtain the $5 \%$ damped acceleration response spectra with soil effects. The acceleration response spectra for the different soil zones in Barcelona are shown in Fig. 9. As can be seen, the soils within Barcelona show considerable amplifications in the short period range (Fig. 7).

\subsection{Earthquake scenarios and design spectra for Barcelona. A comparison}

Figure 10 shows the response spectra for both the deterministic and probabilistic scenarios together with the design spectra provided by the Spanish seismic code (NCSE-02 2002). As can be seen, for periods lower than $0.4 \mathrm{~s}$ the obtained deterministic response spectrum gives higher spectral accelerations than the response spectra recommended for a rock site condition in Barcelona by the NCSE-02. On the contrary, for periods higher than $0.4 \mathrm{~s}$, the response spectra recommended by the NCSE-02 give spectral accelerations higher than the deterministic response spectrum obtained in this study. The rock site condition probabilistic acceleration response spectrum obtained in this study for a return period of 475 years gives 


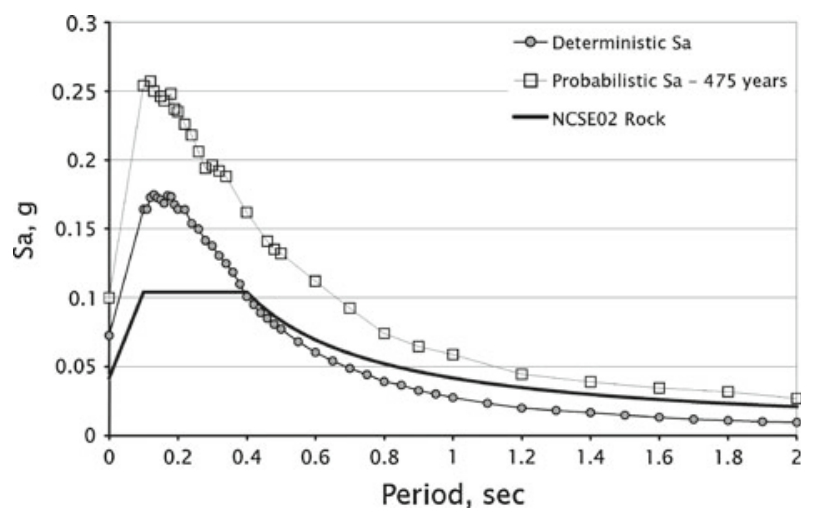

Fig. 10 Comparison between the deterministic and probabilistic $S a$ and the $S a$ recommended by the NCSE-02 for a rock site condition in Barcelona

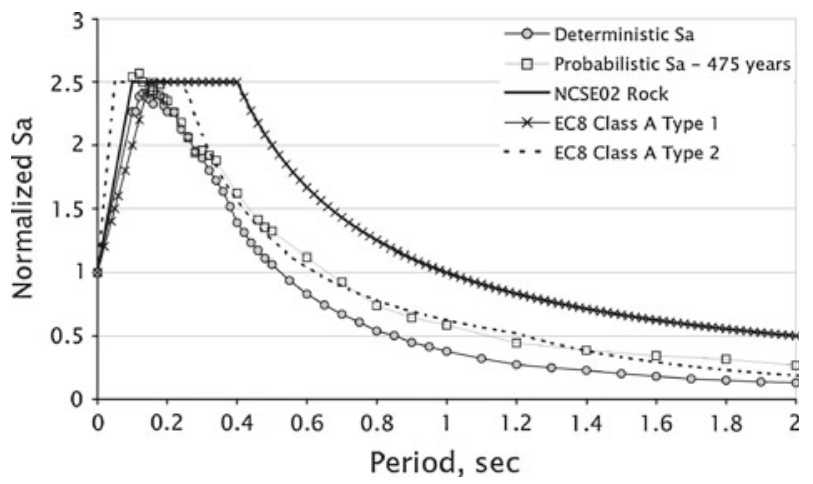

Fig. 11 Comparison between the normalized deterministic and probabilistic $S a$ and the normalized $S a$ recommended by the NCSE-02 and Eurocode- 8 for a rock site condition in Barcelona

higher spectral accelerations than the acceleration response spectrum recommended by the NCSE-02 for similar soil conditions.

The normalized acceleration response spectra obtained for a rock site condition in Barcelona are compared in Fig. 11 to the corresponding normalized horizontal elastic response spectra recommended by the NCSE-02 and Eurocode-8 (CEN 2003). For all the considered periods, the normalized deterministic response spectrum is lower than the one recommended by the NCSE-02 and Eurocode- 8 for both types. The normalized probabilistic response spectrum is lower than the response spectra recommended by the NCSE-02 and the Eurocode- 8 Type 1, but very similar to the Eurocode- 8 Type 2 spectrum, although it is higher for some periods.

In order to analyze the feasibility of the 5\% damped elastic response spectra obtained for soft soils, the European Strong Motion Database (Ambraseys et al. 2000) is used. In a first step, the Ambraseys et al. (1996) attenuation law was used to determine that, for the probabilistic scenario and for rock site conditions, the $5 \%$ damped elastic response spectrum roughly corresponds to earthquakes with surface wave magnitude close to $5(\mathrm{Ms} \approx 5)$, as the strongest earthquake within seismic source zone 2, where the city is located (see Fig. 3), has a surface wave magnitude of 5.1 and epicentral distance up to $10 \mathrm{~km}(\Delta \approx 10 \mathrm{~km})$ (Irizarry 
2004). Then, in this strong motion database, it was performed a search for accelerograms corresponding to earthquakes of similar epicentral parameters recorded in analogous soft soil conditions. Figure 12 shows representative examples of the obtained results. The 5\% damped elastic response spectrum of six strong motion records, together with the target response spectra are shown in this Figure. Two of them show a reasonably good agreement with the response spectra corresponding to the zones I, II, and III. Two more are shown for the zones II and III and, finally, the other two are plotted only in the case of the zone I. Taking into account the crudity of this comparison, which is mainly due to the difficulty of knowing the specific soil conditions of the site where the selected accelerograms were recorded, we conclude that, this exercise is a sort of validation of the amplification factors used to obtain the response spectra for soft soils starting from the one obtained for rock site conditions. Actually it can be seen in Fig. 12 that the 5\% damped elastic response spectra for soils obtained using the spectral amplification factors calculated in this work are within the spectral amplification levels exhibited by these real acceleration response spectra corresponding to accelerograms recorded in similar soft soils.

\subsection{Acceleration-displacement response spectra (ADRS)}

The deterministic and probabilistic scenarios defined here by means of 5\% damped response spectra represent credible ground shaking levels for Barcelona. Code based design spectra define the seismic actions to be used in the design and construction of buildings and facilities in order to protect them against earthquakes. Force based design methods use the periodacceleration format of the response spectra. Modern performance based earthquake design techniques use the $S a-S d$ format (ADRS) for the response spectrum, that is, the spectral acceleration, $S a$, in the $y$-axis and the spectral displacement, $S d$, in the $x$-axis.

The inelastic reduced response spectrum for a given building is also called demand spectrum. The following equation from Newmark and Hall (1982) allows obtaining elastic ADRS from the acceleration-period format response spectrum:

$$
S_{d}=S_{a}\left[\frac{T^{2}}{4 \pi^{2}}\right]
$$

Specific elastic ADRS response spectra were obtained for the deterministic and probabilistic scenarios for Barcelona. This format is needed to obtain the performance point that allows knowing the maximum displacement a building defined by means of its capacity spectrum will suffer when subjected to a seismic action defined by its response spectrum. Figure 13 shows the acceleration-displacement response spectra corresponding to the probabilistic scenario defined for Barcelona.

The analytical formulation of Eq. 3 was adjusted by Irizarry (2004) for the smoothed acceleration response spectra for Barcelona's soil zones. These simple analytical formulations make easier to use these results in risk studies of large urban areas. Table 1 shows the values of the parameters of the model fitted for the soils zones of Barcelona for both the deterministic and probabilistic scenarios. Figure 14 shows the smoothed ADRS corresponding to Barcelona's soil zones for the probabilistic scenario that was obtained using the analytical formulation from Eq. 3. Response spectra in the ADRS format are crucial for risk evaluation by using the capacity spectrum based method. 

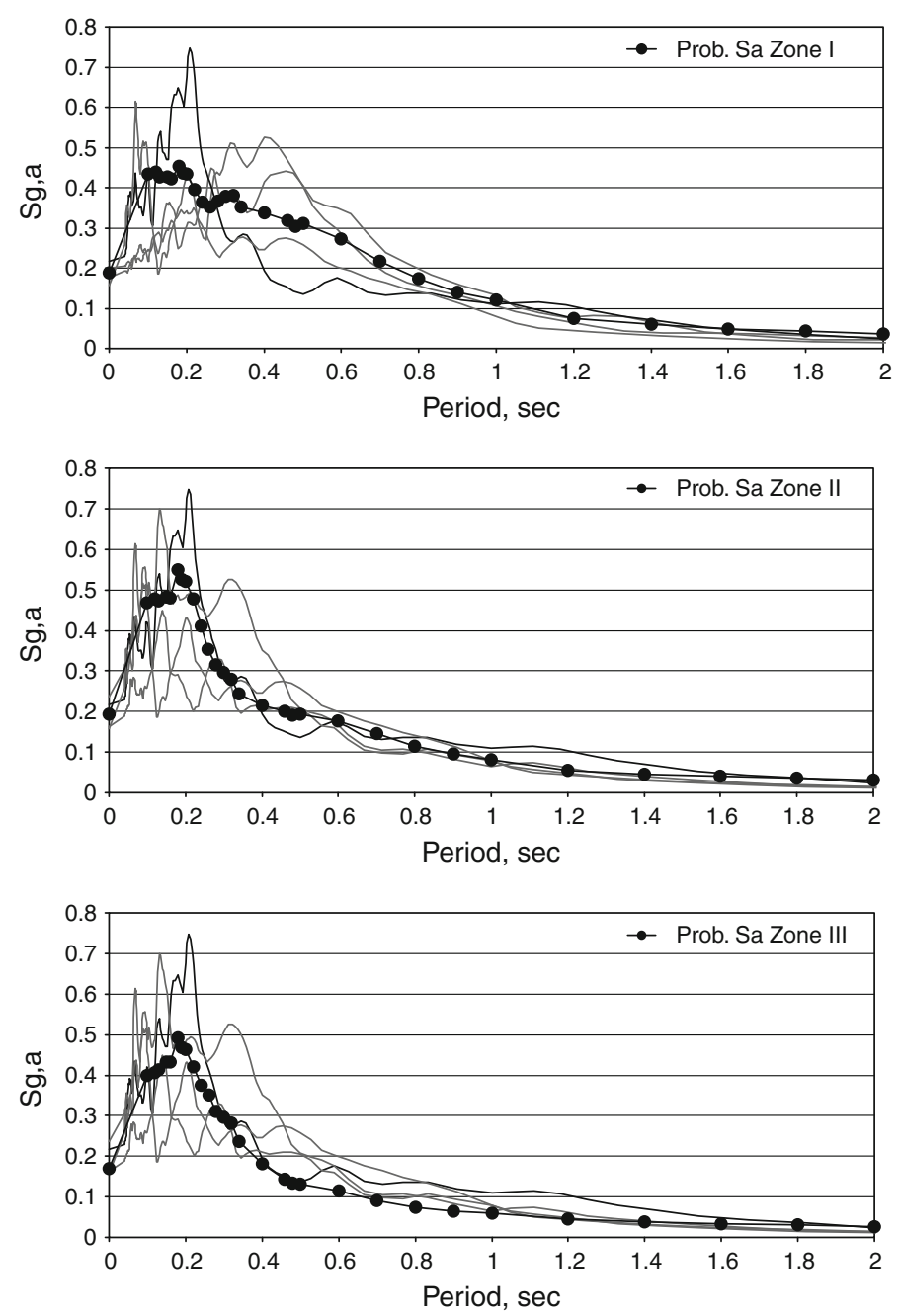

Fig. 12 Comparison between the probabilistic 5\% damped acceleration lineal response spectra for the soil zones in Barcelona and the 5\% damped lineal response spectra for real acceleration records on soft soil

$$
\begin{aligned}
& 0 \leq T \leq T_{B} \quad S_{a}(T)=p g a\left[1+\frac{T}{T_{B}}\left(B_{c}-1\right)\right] \\
& T_{B} \leq T \leq T_{C} \quad S_{a}(T)=p g a * B_{C} \\
& T_{C} \leq T \leq T_{D} \quad S_{a}(T)=p g a\left[\frac{T_{C}}{T}\right]^{d} B_{C} \\
& T \geq T_{D} \quad S_{a}(T)=p g a\left[\frac{T_{D}}{T}\right]^{2} B_{D}
\end{aligned}
$$




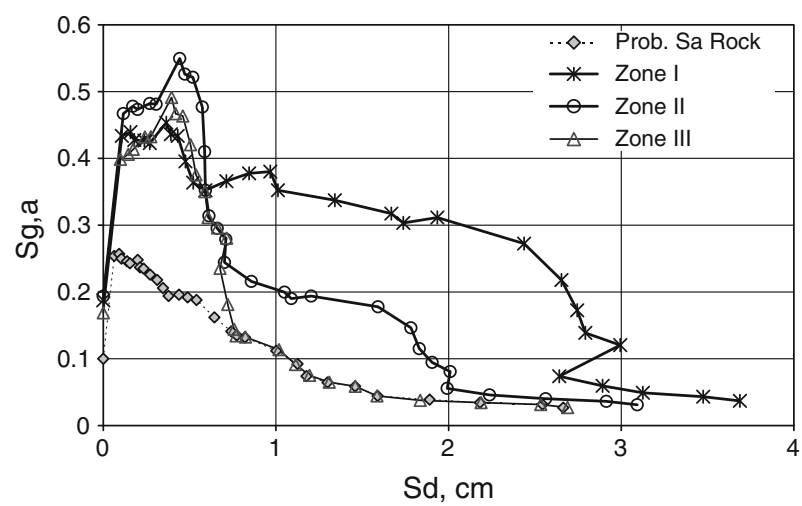

Fig. 13 Probabilistic acceleration-displacement spectra (ADRS) for Barcelona's soil zones

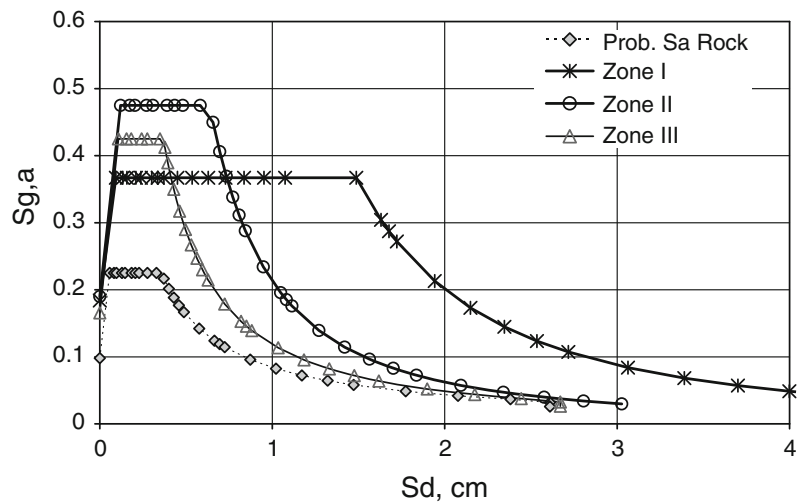

Fig. 14 Smoothed form of the probabilistic acceleration-displacement spectra (ADRS) for Barcelona's soil zones

\section{Capacity spectrum based method}

Damage is assessed by using a Capacity Spectrum Based Method (CSBM). In this method, the earthquake is represented by $5 \%$ damped elastic response spectrum, in $S d$-Sa format (ADRS); earthquake scenarios are selected according to the seismic hazard of the study area. Buildings are described by means of bilinear capacity spectra which are defined by the yielding point $(D y, A y)$ and the ultimate capacity point ( $D u, A u)$ (see Fig. 15); capacity spectra are obtained for representative buildings by means of pushover analysis. Taking into account the inelastic behaviour of the structure, the elastic response spectrum is reduced to the so called demand spectrum. Crossing demand and capacity spectra leads obtaining the performance point (Fajfar and Gaspersic 1996; Fajfar 2002; ATC-40 1996), Milutinovic and Trendafiloski (2003) provide three methods to determine this point. The performance point defines the spectral displacement that the considered seismic demand will produce on the building. Then, the expected damage is evaluated by using fragility curves.

For a specific building type and for a defined damage state $\left(D S_{k}\right)$, the corresponding fragility curve defines the probability of reaching or exceeding $D S_{k}$. Four non-null damage states are considered: Slight $\left(D S_{1}\right)$, Moderate $\left(D S_{2}\right)$, Severe $\left(D S_{3}\right)$ and Complete $\left(D S_{4}\right)$. For the $\operatorname{null}\left(D S_{0}\right)$ damage state the fragility curve is trivially equal to one. For non-null damage 
Table 1 Parameters for the acceleration response spectra for each soil zone

\begin{tabular}{|c|c|c|c|}
\hline Zone & Parameter & Deterministic & Probabilistic \\
\hline \multirow[t]{7}{*}{ I } & $\mathrm{pga}\left(\mathrm{cm} / \mathrm{s}^{\wedge} 2\right)$ & 133 & 184 \\
\hline & $T_{b}(\mathrm{~s})$ & 0.10 & 0.10 \\
\hline & $T_{C}(\mathrm{~s})$ & 0.39 & 0.40 \\
\hline & $B_{c}$ & 1.91 & 2.00 \\
\hline & $D$ & 1.70 & 1.34 \\
\hline & $T_{d}(\mathrm{~s})$ & 2.30 & 2.85 \\
\hline & $B_{d}$ & 0.09 & 0.14 \\
\hline \multirow[t]{7}{*}{ II } & $\mathrm{pga}\left(\mathrm{cm} / \mathrm{s}^{\wedge} 2\right)$ & 138 & 190 \\
\hline & $T_{b}(\mathrm{~s})$ & 0.10 & 0.10 \\
\hline & $T_{c}(\mathrm{~s})$ & 0.22 & 0.23 \\
\hline & $B_{c}$ & 2.45 & 2.50 \\
\hline & $D$ & 1.43 & 1.28 \\
\hline & $T_{d}(\mathrm{~s})$ & 2.20 & 2.21 \\
\hline & $B_{d}$ & 0.09 & 0.14 \\
\hline \multirow[t]{7}{*}{ III } & $\mathrm{pga}\left(\mathrm{cm} / \mathrm{s}^{\wedge} 2\right)$ & 120 & 166 \\
\hline & $T_{b}(\mathrm{~s})$ & 0.10 & 0.10 \\
\hline & $T_{c}(\mathrm{~s})$ & 0.22 & 0.19 \\
\hline & $B_{c}$ & 2.29 & 2.57 \\
\hline & $d$ & 1.40 & 1.12 \\
\hline & $T_{d}(\mathrm{~s})$ & 2.00 & 1.77 \\
\hline & $B_{d}$ & 0.10 & 0.20 \\
\hline \multirow[t]{7}{*}{ Rock } & $\mathrm{pga}\left(\mathrm{cm} / \mathrm{s}^{\wedge} 2\right)$ & 71 & 98 \\
\hline & $T_{b}(\mathrm{~s})$ & 0.10 & 0.10 \\
\hline & $T_{c}(\mathrm{~s})$ & 0.23 & 0.25 \\
\hline & $B_{c}$ & 2.26 & 2.29 \\
\hline & $d$ & 1.12 & 0.98 \\
\hline & $T_{d}(\mathrm{~s})$ & 1.75 & 1.75 \\
\hline & $B_{d}$ & 0.23 & 0.34 \\
\hline
\end{tabular}

states, it is assumed that fragility curves are represented by lognormal distribution functions, as given by the following equation (FEMA/NIBS 2002):

$$
\wp_{k}(S d)=P\left(D S \geq D S_{k} \mid S d\right)=\Phi\left[\frac{1}{\beta_{k}} \ln \left(\frac{S d}{\overline{S d_{k}}}\right)\right] \quad k=1, \ldots, 4
$$

In this equation, $\Phi$ is the standard lognormal cumulative distribution function, $S d$ is the inelastic spectral displacement. $\overline{S d_{k}}$ and $\beta_{k}$ are respectively the mean value and the standard deviation of the normal distribution associated to the lognormal distribution. Therefore, $\overline{S d_{k}}$ is the median (50th percentile) of the lognormal distribution and $\beta_{k}$ reflects the dispersion of the random variable $S_{d}$.

The simplified method suggested in the Risk-UE project is used to estimate these parameters (Milutinovic and Trendafiloski 2003; Lagomarsino and Giovinazzi 2006; Barbat et al. 
Fig. 15 Capacity spectrum and damage states thresholds (see also Table 2)
Table 2 Damage states thresholds defined according to the capacity spectrum (see also Fig. 15)

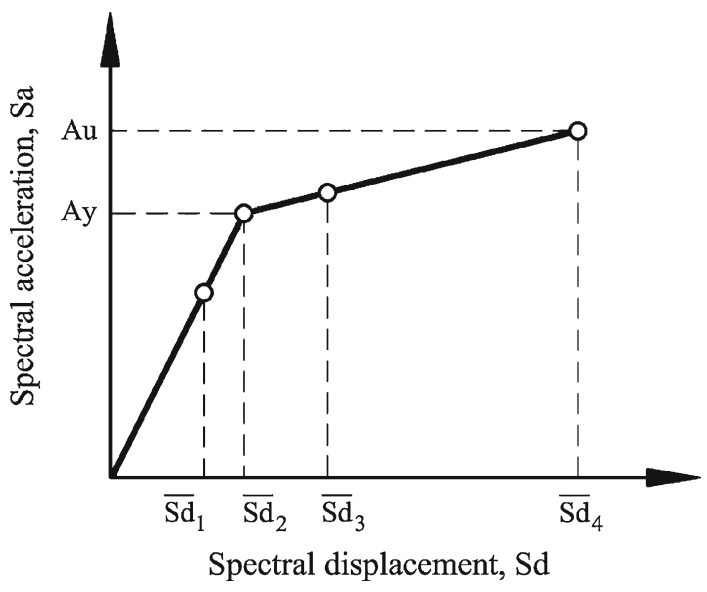

2006). Median $\overline{S d_{k}}$ values, also called damage state thresholds, are obtained from the capacity spectra.

Figure 15 and Table 2 show how these values are obtained from capacity spectra for damage states $D S_{1}, D S_{2}, D S_{3}$ and $D S_{4}$.

In order to estimate $\beta_{k}$ it is assumed that, at the spectral displacement corresponding to the damage states thresholds, $\overline{S d_{k}}$, the expected seismic damage follows a binomial probability distribution (Grünthal 1998), which is defined by the following equation:

$P_{k}=P\left(D S=D S_{k}\right)=P_{k}(N, d)=\frac{(N-1) !}{(N-1-k) ! k !} d^{k}(1-d)^{N-1-k} \quad k=0, \ldots,(N-1)$

where $N$ is the total number of damage grades (here $N=5$ ) and $d$ takes values between 0 and $1 ; d=0$ means no damage, whereas $d=1$ means that the complete damage grade is expected with a probability equal to 1 .

Equivalent Beta probability functions can also be used to quantify the probabilities of occurrence of the damage states. The value of $d$ is related to the mean damage grade, $D S_{m}$, by the following equation:

$$
d=\frac{D S_{m}}{N-1} ; \quad \text { being } \quad D S_{m}=\sum_{k=0}^{N-1} k P_{k}(N, d)
$$

$D S_{m}$ takes values between 0 and $N-1, N=5$ in this case.

For any spectral displacement $(S d)$ the probabilities of occurrence, $P_{k}$, in Eq. (5), and the probabilities of exceedance, $\wp_{l}$ in Eq. (4), of the damage states are linked by the following equation: 
Table 3 Probabilities of exceedance $\left(\wp_{k}\right)$ and probabilities of occurrence $\left(P_{k}\right)$ of the damage states (DSk) at the damage states thresholds

\begin{tabular}{|c|c|c|c|c|c|c|c|c|c|c|c|c|}
\hline \multirow[t]{2}{*}{ Condition } & \multirow[t]{2}{*}{$S d$} & \multicolumn{4}{|c|}{$\wp_{k}(S d)=P\left(D S \geq D S_{k} \mid S d\right)$} & \multicolumn{5}{|c|}{$P_{k}=P\left[D S=D S_{k}\right]$} & \multirow[t]{2}{*}{$D S_{m}$} & \multirow[t]{2}{*}{$d$} \\
\hline & & $D S_{1}$ & $D S_{2}$ & $D S_{3}$ & $D S_{4}$ & $D S_{0}$ & $D S_{1}$ & $D S_{2}$ & $D S_{3}$ & $D S_{4}$ & & \\
\hline$\wp_{1}\left(\overline{S d_{1}}\right)=0.5$ & $\overline{S d_{1}}$ & 0.500 & 0.122 & 0.015 & 0.001 & 0.500 & 0.378 & 0.107 & 0.014 & 0.001 & 0.636 & 0.159 \\
\hline$\wp_{2}\left(\overline{S d_{2}}\right)=0.5$ & $\overline{S d_{2}}$ & 0.858 & 0.500 & 0.163 & 0.022 & 0.142 & 0.358 & 0.337 & 0.141 & 0.022 & 1.543 & 0.386 \\
\hline$\wp_{3}\left(\overline{S d_{3}}\right)=0.5$ & $\overline{S d_{3}}$ & 0.978 & 0.837 & 0.500 & 0.142 & 0.022 & 0.141 & 0.337 & 0.358 & 0.142 & 2.457 & 0.614 \\
\hline$\wp_{4}\left(\overline{S d_{4}}\right)=0.5$ & $\overline{S d_{4}}$ & 0.999 & 0.985 & 0.878 & 0.500 & 0.001 & 0.014 & 0.107 & 0.378 & 0.500 & 3.364 & 0.841 \\
\hline
\end{tabular}

For each damage state, DSk, it is assumed that $\wp_{k}$ at $\overline{S d_{k}}$ is $50 \%$ ( 0.500 bold text in Table). d defines the binomial probability distribution given in Eq. (5) and DSm is the mean damage state (see explanation in the text)

$$
\wp_{k}(S d)=P\left(D S \geq D S_{k}\right)=\sum_{l=k}^{N-1} P_{l}=\sum_{l=k}^{N-1} P\left[D S=D S_{l}\right] \quad k=0, \ldots,(N-1)
$$

Therefore, taking into account that when $S d$ is equal to $\overline{S d_{k}}$, the probability of equalling or exceeding the damage state $k$ is $50 \%$, the probabilities of the other damage states are estimated from the corresponding Binomial probability distribution. For example, when the probability of equalling or exceeding the damage state 1 (slight) is 0.5 , the occurrence probabilities of the damage states 0, 1, 2, 3 and 4, computed by using Eq. (5), are respectively $0.500,0.378,0.107,0.014$ and 0.001 , whereas the corresponding exceedance probabilities of the damage states $1,2,3$ and 4 are $0.500,0.122,0.015$ and 0.001 . Table 3 shows the occurrence and exceedance probabilities of the damage states at the mean spectral displacements corresponding to the damage states thresholds.

In particular Fig. 16 shows a plot of the probabilities corresponding to the mean spectral displacement thresholds deduced from the capacity curve for an example of unreinforced masonry building (Bonett 2003). A least squares fit leads to estimate $\beta_{k}$ parameters thus providing a complete definition of the corresponding fragility curves. Typical fragility curves, as

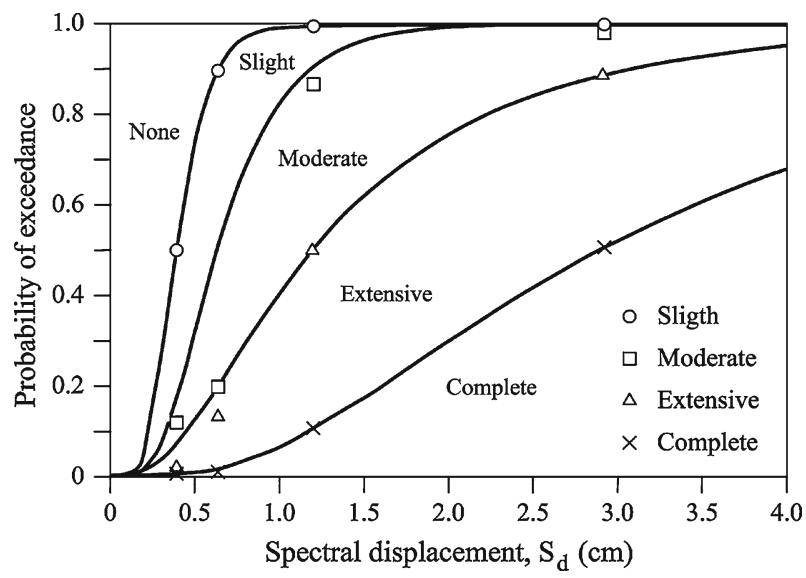

Fig. 16 Fragility curves for mid-rise unreinforced masonry buildings fitted to the obtained points of Table 3 by means of a least square criterion (Bonett 2003; Barbat et al. 2008) 


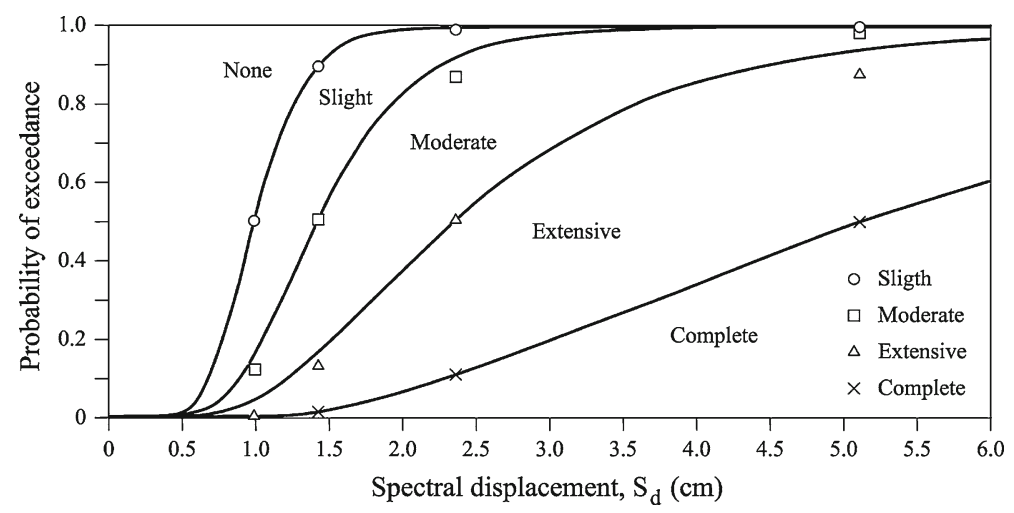

Fig. 17 Fragility curves for mid-rise reinforced concrete buildings fitted to the obtained points of Table 3 by means of a least square criterion (Moreno et al. 2004; Barbat et al. 2008)

Table 4 Most probable damage state as a function of the mean damage state values (see Eq. 6)

\begin{tabular}{ll}
\hline Mean damage index intervals $\left(D S_{m}\right)$ & Most probable damage state \\
\hline $0.0-0.5$ & None \\
$0.5-1.5$ & Slight \\
$1.5-2.5$ & Moderate \\
$2.5-3.5$ & Extensive \\
$3.5-4.0$ & Complete \\
\hline
\end{tabular}

functions of the spectral displacement, for unreinforced masonry buildings and for reinforced concrete buildings are shown respectively in Fig. 16 and in Fig. 17. The values of Table 3, corresponding to the fragility curves at the damage states thresholds, are also shown in these figures.

Finally, for each building and for each earthquake scenario, the spectral displacement of the corresponding performance point enables to determine the exceedance probabilities, and, therefore the probabilities of occurrence, of the damage states by entering this value into the appropriate fragility curves. These probabilities of occurrence of the different damage states are also called damage probability matrices (DPM).

The mean damage state, as defined in Eq. 6, is very useful for mapping and analyzing damage distributions by using a single parameter. In these cases it is also useful to link mean damage state values and the most likely damage state. Table 4 shows the correspondences between the values of $D S_{m}$ and the discrete damage states $D S_{k}$. Of course, alternative maps may also plot the spatial distribution of the probability of occurrence of a specified damage state $D S_{k}$, that is $P_{k}$.

\section{Seismic risk evaluation for the city of Barcelona}

This section is devoted to risk analysis. It is worth noting that, for management purposes, risk requires a multidisciplinary evaluation that takes into account not only the expected physical damage, but also damage to population and economic losses (ATC-13 1985; Coburn and Spence 2002; Vacareanu et al. 2004) as well as other societal and policy related aspects 
(Carreño et al. 2007; Barbat et al. 2010). First, the expected direct physical damage to dwellings is analyzed, and then casualties, economic losses and volume of debris produced by such seismic crises are estimated. For the two seismic scenarios developed in the previous sections, DPM are obtained by using specific capacity spectra and fragility curves developed for structures representative of the dwelling buildings of Barcelona. Although damage is assessed building by building (Lantada et al. 2009), in this section the spatial distribution of the seismic risk results are summarized and represented for the ten districts of Barcelona.

\subsection{Physical direct damage for residential buildings}

Throughout the years, detailed information on the design and constructive peculiarities of the existing buildings has been obtained by collecting and completing a reliable database of the dwellings of the city of Barcelona. All the available data have been integrated into a Geographic Information System (GIS), which includes more than 60,000 residential buildings and provides information about the distribution of building stock according to structural system, year of construction and number of stories.

Almost the $80 \%$ of housing in Barcelona was constructed prior to the first Spanish Seismic Code (PGS-1 1968) and the 97\% of them are unreinforced masonry and reinforced concrete buildings. Most of the reinforced concrete buildings of Barcelona have waffled-slabs, a typology usually not recommended for seismic areas (Vielma et al. 2008). Most of them have a soft first storey. In extreme cases, their vulnerability is comparable with that of low quality unreinforced brick masonry buildings. Detailed information on the design and construction of the buildings of Barcelona can be seen in Lantada et al. (2009), Barbat et al. (2008, 2010).

Capacity curves and damage probability matrices were obtained for six different buildings classes that characterize the building stock of the city: low-rise (2 floors), mid-rise (4 floors) and high-rise (6 floors) of masonry buildings (Bonett 2003) and low-rise (2 floors), mid-rise (5 floors) and high-rise (8 floors) concrete buildings (Moreno et al. 2004)

Table 5 shows the mean damage index for low, mid and high-rise masonry and concrete buildings respectively located in different zones of the seismic microzonation of the city and for deterministic and probabilistic hazard scenarios. Starting from these mean damage grades, damage probability matrices can be obtained (Barbat et al. 2008). Damage expected for mid and high rise masonry buildings are high for relative small earthquakes. For example, in the probabilistic seismic scenario, an Extensive damage state is expected for mid and high rise masonry buildings located in Zone I (mean damage index of 2.81 and 2.98 respectively).

Unreinforced masonry structures show higher maximum damage grades and also lower minimum damage grades than reinforced concrete buildings. Maximum damage values are expected for high rise masonry buildings located on soft soils (Zone I) and for the probabilistic hazard scenario.

Figures 18 and 19 show the distribution of the damage among the six building classes analyzed for the deterministic and probabilistic hazard scenarios respectively for the totality of buildings in the city.

The mid rise and high rise masonry buildings would suffer the damages, especially for probabilistic hazard scenario, with moderate damages for the $89 \%$ of these buildings. However, not important damages are expected for reinforced concrete buildings, except for the low rise buildings. Moderate damages are expected for the $54 \%$ of these buildings, according to the probabilistic hazard scenario.

Thank to the detail and quality of the GIS database of the city, and using these damage probability matrices, building by building damage scenarios were built. However, for a better interpretation of the results the mean damage grade (Eq. 6), these values have been summa- 
Table 5 Mean damage grades, DSm for masonry and reinforced concrete buildings in Barcelona, for deterministic and probabilistic seismic hazard scenarios (zones corresponding to the seismic microzonation of the city: R-Rocky outcrops, I - Soft soils)

\begin{tabular}{|c|c|c|c|c|c|c|c|}
\hline & \multirow[t]{2}{*}{ Zone } & \multicolumn{3}{|c|}{ Unreinforced masonry } & \multicolumn{3}{|c|}{ Reinforced concrete } \\
\hline & & $\begin{array}{l}\text { Low-rise } \\
\text { (1-2 } \\
\text { floors) }\end{array}$ & $\begin{array}{l}\text { Mid-rise } \\
\text { (3-5 } \\
\text { floors) }\end{array}$ & $\begin{array}{l}\text { High-rise } \\
(\geq 6 \text { floors })\end{array}$ & $\begin{array}{l}\text { Low-rise } \\
\text { (1-3 } \\
\text { floors) }\end{array}$ & $\begin{array}{l}\text { Mid-rise } \\
\text { (4-7 } \\
\text { floors) }\end{array}$ & $\begin{array}{l}\text { High-rise } \\
\text { ( } \geq 8 \text { floors) }\end{array}$ \\
\hline \multirow{4}{*}{$\begin{array}{l}\text { Deterministic } \\
\text { scenario }\end{array}$} & I & 0.07 & 2.34 & 2.40 & 1.96 & 1.23 & 0.82 \\
\hline & II & 0.35 & 1.60 & 1.56 & 1.33 & 0.44 & 0.30 \\
\hline & III & 0.11 & 1.25 & 1.16 & 0.89 & 0.21 & 0.10 \\
\hline & $\mathrm{R}$ & 0.00 & 0.64 & 0.57 & 0.34 & 0.11 & 0.11 \\
\hline \multirow{4}{*}{$\begin{array}{l}\text { Probabilistic } \\
\text { scenario }\end{array}$} & I & 0.50 & 2.81 & 2.98 & 2.05 & 1.51 & 1.19 \\
\hline & II & 1.07 & 2.31 & 2.44 & 1.61 & 0.83 & 0.68 \\
\hline & III & 0.81 & 2.01 & 2.15 & 1.30 & 0.53 & 0.44 \\
\hline & $\mathrm{R}$ & 0.03 & 1.60 & 0.50 & 0.78 & 0.44 & 0.52 \\
\hline
\end{tabular}
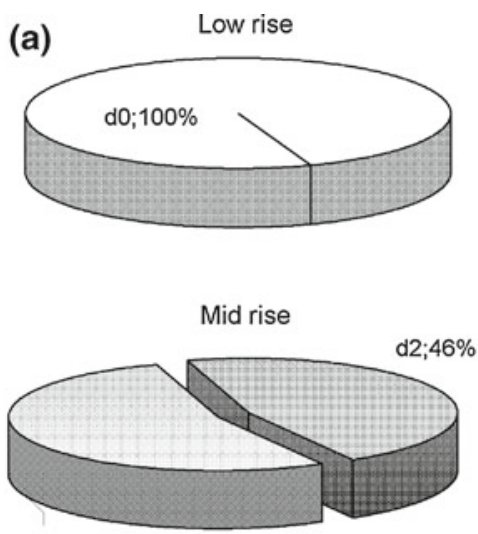

$\mathrm{d} 1 ; 54 \%$

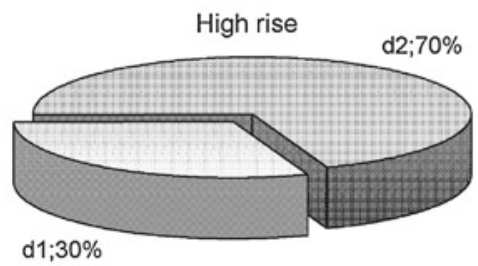

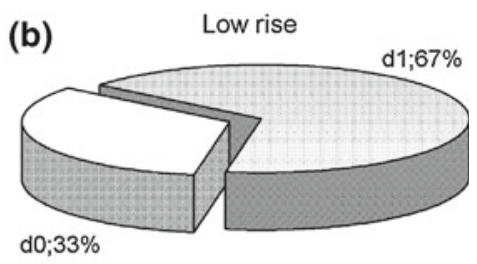

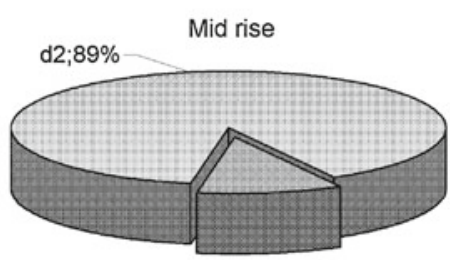

d3; $11 \%$

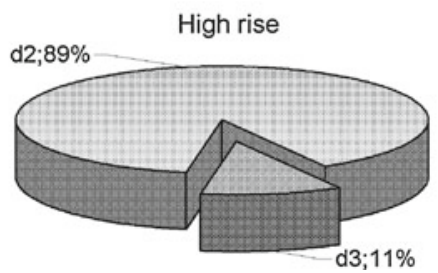

Fig. 18 Damage distribution (mean damage index) of unreinforced masonry buildings according to number of stories for deterministic and probabilistic hazard scenarios

rized by administrative zones. In general, damage values of buildings are close to Slight and Moderate damage state for deterministic and probabilistic hazard scenarios respectively.

The mean damage grade is 0.86 for the deterministic hazard scenario, while for the probabilistic case it is 1.51 , which respectively corresponds to slight and moderate damage states 

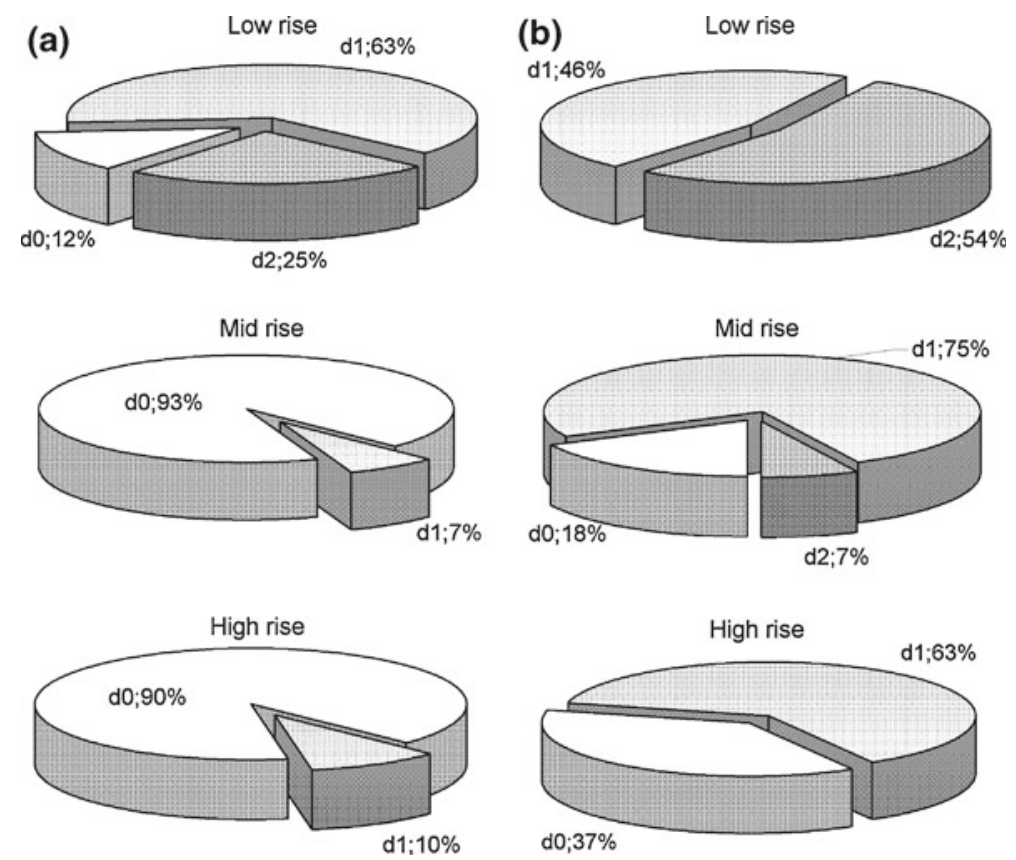

Fig. 19 Damage distribution (mean damage index) of reinforced concrete buildings according to number of stories, $\mathbf{a}$ for deterministic and $\mathbf{b}$ probabilistic hazard scenarios

according to Table 2. The distribution of damage follows a radial pattern from downtown to the outskirts of Barcelona, In both cases, the highest damage expected is located in the downtown (01-Ciutat Vella district), were a moderate damage state is expected (1.8 and 2.5 in the deterministic and probabilistic hazard cases, respectively).

\subsection{Population casualties rates}

The casualties are estimated for four injury severity levels (mortally injured, life threatening injuries, injuries that require hospitalization and light injuries), according to the casualty model given by Coburn and Spence (2002). The occupancy rate of each building has been evaluated by assuming that reinforced concrete buildings contain more dwelling units and therefore more people due to their bigger size. Concerning the total floor area of masonry and reinforced concrete buildings, reasonable weights of 45 and 55\% were assumed for masonry and concrete buildings, respectively. Thus, from the number of inhabitants for each census area, the number of inhabitants for each type of building has been estimated. The results obtained correspond to the distribution of population during a work day at night, with occupancy at time of earthquake of $80 \%$ for residential buildings.

Other important information that should be considered for disaster management in a city is the number of persons that must be relocated due to the uninhabitable dwelling units. The methodology to determine the number of uninhabitable residential units due to structural damage $\left(U N U_{S D}\right)$, is based on HAZUS (1999). Based on comparisons with previous works (Perkins et al. 1996), the methodology considers as $U N U_{S D}$ the $100 \%$ of residential units located in buildings that are in the very heavy and destruction damage state and the $90 \%$ that are in substantial to heavy damaged structures. Therefore, the total number of persons 
Table 6 Summary of risk scenarios by districts

\begin{tabular}{|c|c|c|c|c|c|c|c|c|c|c|}
\hline \multirow[t]{2}{*}{ Districts name } & \multicolumn{5}{|c|}{ Deterministic hazard scenario } & \multicolumn{5}{|c|}{ Probabilistic hazard scenario } \\
\hline & $\mathrm{D}$ & In & $\mathrm{H}$ & Cost & De & $\mathrm{D}$ & In & $\mathrm{H}$ & Cost & $\mathrm{De}$ \\
\hline 01-Ciutat Vella & 1.0 & 1.6 & 175.6 & 653 & 602 & 3.3 & 3.0 & 331.4 & 1243 & 1232 \\
\hline 02-Eixample & 1.0 & 0.8 & 87.0 & 981 & 926 & 2.9 & 2.0 & 206.0 & 2247 & 2296 \\
\hline 03-Sants-Montjuïc & 1.0 & 0.8 & 82.5 & 804 & 864 & 2.7 & 1.7 & 172.8 & 1653 & 1814 \\
\hline 04-Les Corts & 0.8 & 0.5 & 38.5 & 105 & 116 & 2.6 & 1.4 & 92.0 & 258 & 306 \\
\hline 05-Sarrià-StGervasis & 0.1 & 0.2 & 36.8 & 261 & 234 & 1.1 & 0.1 & 107.0 & 734 & 745 \\
\hline 06-Gràcia & 0.3 & 0.4 & 59.8 & 264 & 241 & 1.5 & 1.1 & 148.2 & 637 & 635 \\
\hline 07-Horta-Guinardó & 0.1 & 0.1 & 33.7 & 185 & 165 & 0.7 & 0.5 & 95.1 & 499 & 488 \\
\hline 08-Nou Barris & 0.1 & 0.1 & 39.5 & 146 & 131 & 1.1 & 0.7 & 113.7 & 398 & 399 \\
\hline 09-Sant Andreu & 0.5 & 0.4 & 36.9 & 159 & 167 & 1.7 & 1.0 & 93.6 & 378 & 415 \\
\hline 10-Sant Martí & 1.2 & 0.7 & 89.1 & 84 & 125 & 2.3 & 1.0 & 148.4 & 137 & 205 \\
\hline Barcelona city & 0.6 & 0.6 & 59.2 & 3642 & 3571 & 2.0 & 1.2 & 136.1 & 8184 & 8535 \\
\hline
\end{tabular}

$D$ people died $\left({ }^{o} / o o\right)$; In injured people $\left({ }^{o} /{ }^{o o}\right) ; H$ homeless people $\left({ }^{o} /{ }^{o o}\right)$; Cost structural cost in million of Euros; $D e$ debris volume in tons

displaced from each building $i$ with a typology $t\left(P_{U N U}\right)$, is obtained multiplying the total number of $U N U_{S D}$ by the number of persons who are assumed to live in each household.

Table 6 summarizes the total of casualties, injured people and homeless evaluated for each district of the city, for the deterministic and the probabilistic seismic hazard scenarios. The cause of most of the casualties and injured people is the collapse of reinforced concrete buildings. This is mainly due to the differences between the coefficients proposed by Coburn and Spence (2002) that, in fact, reveal the actual effect of the collapse of certain types of reinforced concrete buildings during past earthquakes (Coburn and Spence 2002). Expected casualties in an urban area are strongly correlated not only with the severity of the hazard scenario but also with the density of population and of the built area. Figures 20 and 21 depict the total casualties and homeless people that can be expected from the considered deterministic and probabilistic earthquake hazard scenarios, respectively.

\subsection{Economic cost}

The economical losses are estimated as the present restoration cost of the damaged buildings. This value is determined by considering that reconstruction is made using reinforced concrete buildings and it does not include the land cost. Two economic cost scenarios have been evaluated in this study. The first one provides the absolute economic cost $\left(S_{\text {Cost }}\right)$ in millions of Euros, given by the following equation:

$$
S_{\text {Cost }}=\sum_{k=2}^{5} C S(k)=V_{C} \cdot \sum_{k=2}^{5} \sum_{j=1}^{N e}\left[\operatorname{Area}(j) \cdot P_{S}(k, j) \cdot R C(k, j)\right]
$$

where $S_{\text {Cost }}$ is the sum of the $C S(k)$ repair costs due to the damage state $k$ (damage state 1 none is not considered, because there is no any induced cost when there is no damage); $V_{C}$ is the cost per unit area for which a constant value of $V_{C}$ is assumed for all building typologies; Area is the building area; $P S(k, j)$ is the probability for the building $\mathrm{j}$ to be in the damage state $k$ and $R C(k, j)$ is the repair value due to the damage state $k$ for the building $j$; 


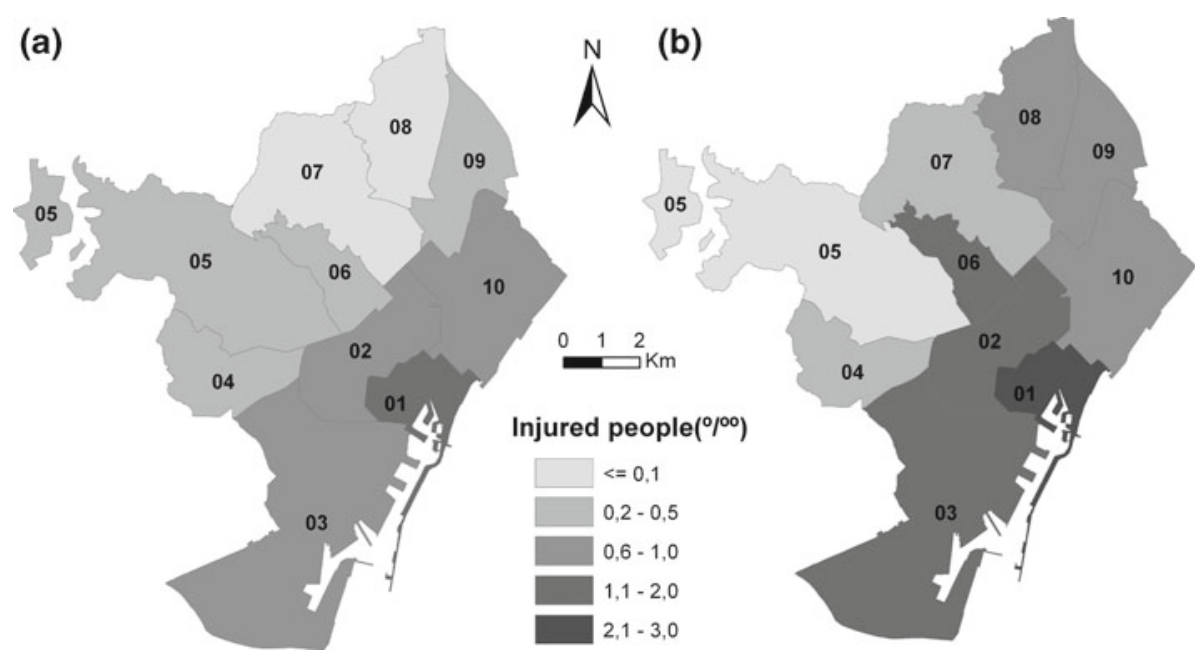

Fig. 20 Distribution of injured people by districts, a deterministic hazard scenario and b probabilistic hazard scenario

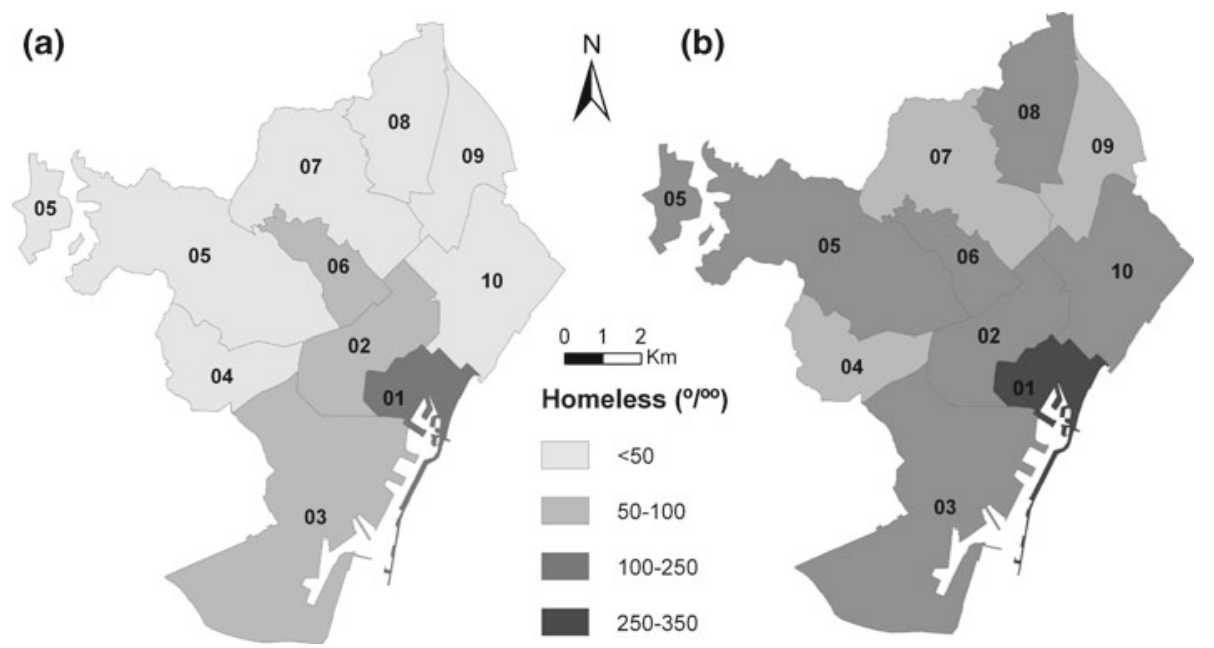

Fig. 21 Homeless people estimated by districts for a deterministic hazard scenario and $\mathbf{b}$ probabilistic hazard scenario

$R C(k, j)$ is given as a percentage of the reposition cost per square meter. A reasonable value of $V_{C}$ for a residential building is $723 € \mathrm{~m}^{2}$ which corresponds to the Spanish construction market (Boletín Económico de la Construcción 2007). The construction cost has increased considerably in the last years (about a $10 \%$ per year) and, taking into account that the final cost depends on these values, the second scenario gives the relative economic cost $\left(R_{\text {Cost }}\right)$, that is, the expected equivalent floor area destroyed by the earthquake.

An additional economic loss due to the damage of residential building contents is about the $50 \%$ of the building restoration value (ATC-13 1985). This value is added to the structural cost, $S_{\text {Cost }}$, in order to obtain the total economic cost $T_{\text {Cost }}$. Table 6 shows the values $S_{\text {Cost }}$ obtained for each district of the city, which have been assumed to be dependent on 


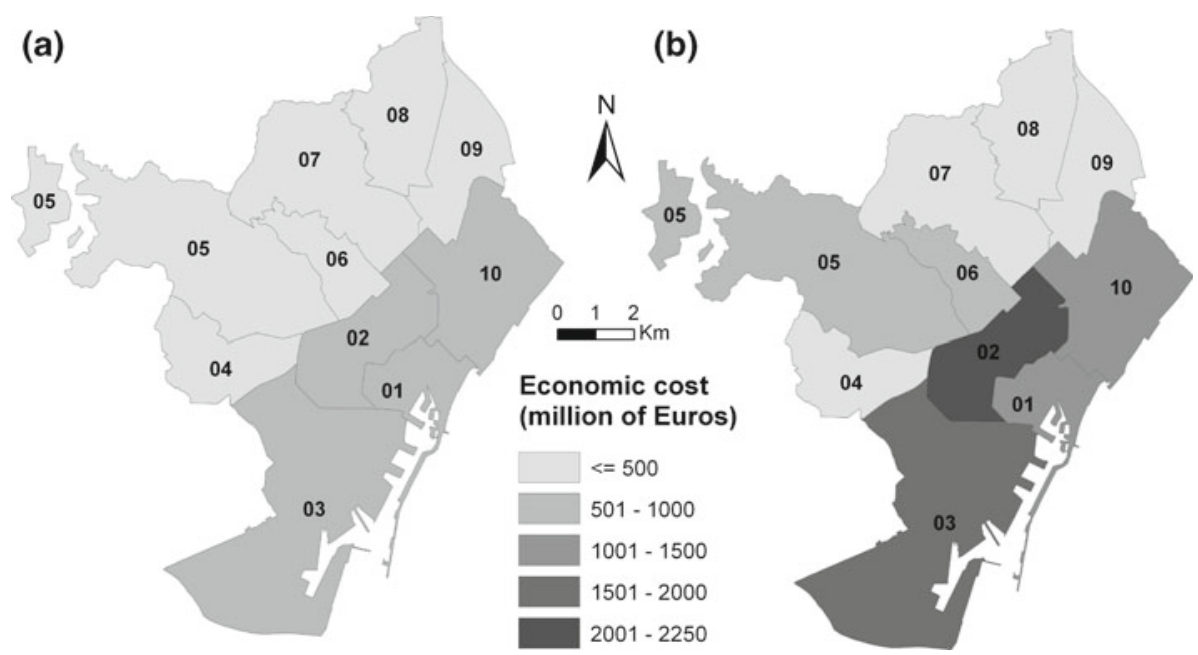

Fig. 22 Total economic cost in million of Euros evaluated by districts for a deterministic hazard scenario and b probabilistic hazard scenario

the damage state $k$ but not on the structural typology. Figure 22 depicts $S_{\text {Cost }}$, in millions of Euros, caused by the considered deterministic and probabilistic earthquake hazard scenarios.

\subsection{Debris generated}

The estimation of debris is performed empirically, based on observations of damage occurred in past earthquakes, for the damage states of the structural and non-structural elements (FEMA/NIBS 2002). Two types of debris are considered: (1) debris that falls in large pieces, e.g. steel members or reinforced concrete elements; (2) smaller debris, such like brick, wood, glass, building contents etc. The total debris weight, in tons, are obtained for each building of typology $t$ and for each debris type $d$, multiplying the built area by the expected debris fraction $E D F s(d, t)$ due to the structural damage state $k$. This fraction is modeled by the following equation:

$$
E D F_{S}(d, t)=\sum_{k=2}^{5} P_{S}(k, t) \cdot D F_{S}(d, k, t)
$$

where $P_{S}(k, t)$ is the probability of a structural damage state $k$ for the building typology $t$ and $D F_{S}(d, k, t)$ is the fraction of debris type $d$ for the building typology $t$ if the structural damage state $k$ occurs. In order to obtain the value of $\operatorname{DFs}(d, k, t)$, the coefficients of structural element weights for different materials of debris type and for the building typology, and the fractions of the structural element weight that is expected to result in debris due to the earthquake have been adapted from HAZUS 1999 (Vacareanu et al. 2004; Barbat et al. 2006).

\subsection{Summary by districts}

Results for seismic risk scenarios simulated for Barcelona are shown in this section. Different seismic risk scenarios for the deterministic and probabilistic hazard are shown for districts from Figs. 20-22. The scenarios of these figures provide average information easy to analyze 
and interpret, useful for preparedness, risk management and emergency planning. Table 6 summarizes the values obtained for each district of the city.

Unreinforced masonry structures show higher maximum damage grades and also lower minimum damage grades than reinforced concrete buildings. Maximum damage values are expected for high rise masonry buildings located on soft soils (Zone I) and for the probabilistic hazard scenario.

In general, the highest values for casualties, injured people, economic cost and debris generated have been obtained for the probabilistic hazard scenario and, in both cases, analyzed for the Ciutat Vella and Example district. This district is the most populated and highest density populated, and its buildings are the most ancients after Ciutat Vella district.

\section{Conclusions}

For the first time, a seismic hazard evaluation in terms of spectral accelerations was performed for the Catalonia region and acceleration response spectra for a rock site condition were obtained for Barcelona. A deterministic acceleration response spectrum was obtained from the combined effect of both a distant and a closer historical earthquake that reflected a PGA value of $0.07 \mathrm{~g}$ for a rock site condition. For a return period of 475 years, the variation within the city of the acceleration response spectrum for a rock site condition was negligible and a single response spectrum was fixed for the whole city with a PGA value of $0.10 \mathrm{~g}$. The software CRISIS 99-18 proved to be a powerful tool for the constant hazard evaluation by providing a user friendly windows interface.

Site effects were included by means of amplification factors to define an acceleration response spectrum for each of the soil zones of the city. The obtained spectral amplification factors compare very well to the amplification proposed by the Eurocode- 8 for similar soils. The deterministic and probabilistic acceleration response spectra including soil effects provide higher spectral accelerations than the response spectra obtained for Barcelona using the NCSE-02. Elastic acceleration-displacement response spectra were obtained for Barcelona's soil zones and adjusted to a smooth analytical form to make easier the programming of the vulnerability assessment process using the capacity spectrum method.

Starting from this description of hazard and based on a complete and highly reliable database for the buildings of the city, the capacity spectrum based method has been applied. Therefore, fragility curves and damage probability matrices have been developed for six building classes, and for the four seismic areas of the city.

The massive application of these damage probability matrices to the whole urban area has been done thanks to a Geographic Information System (GIS). This GIS tool allows obtaining reliable seismic risk scenarios which well represent the $95 \%$ of residential buildings stock in the city.

The results show that in Barcelona, a city located in a low to moderate seismic hazard region, the high seismic vulnerability of the structures leads to a considerable expected risk. The mean damage state expected for Barcelona's residential buildings correspond to a level of Slight and Moderate for the deterministic and probabilistic scenario, respectively.

In general, the results obtained are highly consistent with the historical and modern evolution of the populated area. The highest values of risk evaluation have been obtained for the probabilistic hazard scenario and, in both cases, analyzed for the downtown of the city (Ciutat Vella district) and for the Example district. This district is the most populated and highest density populated, and its buildings are the most ancients after Ciutat Vella district. The evaluation of the damage to the population strongly depends on casualty models. 
The obtained results and conclusions offer a great opportunity to guide the action and decision making in seismic risk prevention and mitigation in big cities.

Acknowledgments This work has been partially sponsored by the Spanish Ministry of Education and Science and with FEDER funds (projects: CGL2004-22325-E, CGL-2005-04541-C03-02/BTE, HABITAT 2030-PSS-380000-2005-14 and SEDUREC-CSD2006-00060) and by the European Commission (RISK-UE Project -EVK4-CT-2000-00014).

\section{References}

Ambraseys NN, Simpson KA, Bommer JJ (1996) Prediction of horizontal response spectra in Europe. Earthq Eng Struct Dyn 25:375-400

Ambraseys NN, Smit P, Berardi R, Rinaldis D, Cotton F, Berge-Thierry C (2000) Dissemination of European strong-motion data. CD-ROM collection. European Council, Environment and Climate Research Programme

ATC-13 (1985) Earthquake damage evaluation data for California, ATC-13. Applied Technology Council, 497 Redwook City, California

ATC-40 (1996) Seismic evaluation and retrofit of concrete buildings. Applied Technology Council, Redwook City

Barbat AH, Pujades LG, Lantada N, Moreno R (2006) Performance of buildings under earthquake in Barcelona, Spain. Computer-Aided Civil Infrastruct Eng 21(8): 573-593. doi:10.1111/j.1467-8667. 2010.00660.x

Barbat AH, Pujades LG, Lantada N, Moreno R (2008) Seismic damage evaluation in urban areas using a capacity spectrum based method: application to Barcelona. Soil Dyn Earthq Eng, special issue Urban earthquake hazard and damage assessment 28(10-11):851-865. doi:10.1016/j.soildyn.2009.12.014

Barbat AH, Carreño ML, Pujades LG, Lantada N, Cardona OD, Marulanda MC (2010) Seismic vulnerability and risk evaluation methods for urban areas. A review with application to a pilot area. Struct Infrastruct Eng 6(1-2): 17-38. doi:10.1080/15732470802663763

Boletín Económico de la Construcción (2007) Revista trimestral de precios del ramo de la construcción. Año LXVIII, trimestre 4. No. 272

Bonett RL (2003) Vulnerabilidad y riesgo sísmico de edificios. Aplicación a entornos urbanos en zonas de amenaza alta y moderada. Ph.D Thesis. Departamento de Ingeniería del Terreno, Cartográfica y Geofísica, Universidad Politécnica de Cataluña, Barcelona

Carreño ML, Cardona OD, Barbat AH (2007) Urban seismic risk evaluation: a holistic approach. Nat Hazards 40:137-172

CEN (2003) Eurocode 8: design of structures for earthquake resistance. Comité Européen de Normalisation, Doc CEN/TC250/SC8/N335, January

Cid J, Susagna T, Goula X, Chavarria L, Figueras S, Fleta J, Casas A, Roca A (2001) Seismic zonation of Barcelona based on numerical simulation of site effects. Pure Appl Geophys 158:1-19

Coburn A, Spence R (2002) Earthquake protection, 2nd edn. Wiley, Chichester

Cornell CA (1968) Engineering seismic risk analysis. Bull Seismol Soc Am 58:1583-1606

Dufumier H (2002) Synthesis of magnitude and focal mechanism computations for the $M \geq 4.5$ earthquakes in France for the period 1995-2000. J Seismol 6:163-181

Faccioli E (2006) Seismic hazard assessment for derivation of earhquake scenarios in Risk-UE. Bull Earthq Eng 4:341-364

Fajfar P, Gaspersic P (1996) The N2 method for the seismic damage analysis of RC buildings. Earthq Eng Struct Dyn 25:23-67

Fajfar P (2000) A non linear analysis method for performance-based seismic design. Earthq Spectra 16(3):573-5924

Fajfar P (2002) Structural analysis in earthquake engineering — a breakthrough of simplified non-linear methods. 12th European conference on earthquake engineering, London

FEMA/NIBS (2002) Earthquake loss estimation methodology, HAZUS-99 service release 2 (SR2) technical 533 manual. National Institute of Building Sciences for the Federal Emergency Management Agency. Washington, DC, p 534

Freeman SA (1978) Prediction of response of concrete buildings to severe earthquake motion. In: Proceedings of Douglas McHenry international symposium on concrete and concrete structures, publication SP-55. American Concrete Institute, Detroit, Michigan, USA 
Freeman SA (1998) The capacity spectrum method. In: Proceedings of the 11th European conference on earthquake engineering, Paris

González M (2000) Simulación post evento de los efectos de un terremoto. Institut Cartogràfic de Catalunya, Informe No. GS-128/00, p 241

Goula X, Godefroy P (1985) Évaluation de l'alea simique regional. Zonage à petite échelle, Génie Parasismique, 207-221

Grellet B, Combes PH, Garnier TH, Phillip H (1993) Sismotectonique de la France Métropolitane. Mémories de la Sociéte Géologique de France, No 164, vol I. p 76

Grünthal G (1998) European macroseismic scale 1998. Centre Européen de Géodynamique et de Séismologie, Luxemburg

HAZUS (1999) Earthquake loss estimation methodology technical manual, prepared by the National Institute of Building Sciences for Federal Emergency Management Agency (FEMA), Washington, DC

Irizarry J (2004) An advanced approach to seismic risk assessment. Application to the cultural heritage and the urban system of Barcelona, PhD Thesis, Universitat Politècnica de Catalunya, Spain, p 406

Lantada N, Pujades LG, Barbat AH (2009) Vulnerability index and capacity spectrum based methods for urban seismic risk evaluation. A comparison. Nat Hazards 51(3): 501-524. doi:10.1007/s11069-007-9212-4

Lagomarsino S, Giovinazzi S (2006) Macroseismic and mechanical models for the vulnerability and damage assessment of current buildings. Bull Earthq Eng, special issue: earthquake scenarios for European cities 4(4):415-443

McGuire R (1976) EQRISK. Evaluation of earthquake risk to site. Fortran computer program for seismic risk analysis. US Geolog Surv Open File Rep 76-67:92

Milutinovic ZV, Trendafiloski GS (2003) WP04 Vulnerability of current buildings. RISK-UE project of the EC: an advanced approach to earthquake risk scenarios with applications to different European towns

Moreno R, Bairán JM, Pujades LG, Aparicio AC, Barbat AH (2004) Evaluación probabilista del comportamiento sísmico de edificios porticados de hormigón armado. Hormigón y acero 231:125-136

Mouroux P, Lebrun B (2006) RISK-UE project: an advanced approach to earthquake risk scenarios with application to different European towns. In: Oliveira CS, Roca A, Goula X (eds) Assessing and managing earthquake risk. Springer, Berlin, pp 479-508

Mouroux P, Lebrun B (2006) Presentation of RISK-UE Project. Bull Earthq Eng, special issue: earthquake scenarios for European cities 4(4):323-339

NCSE-02 (2002) Normativa de Construcción Sismorresistente Española, Comisión Permanente de Normas Sismorresistentes, Real Decreto 997/2002. Boletín Oficial del Estado No. 244 del 11 de octubre de 2002

Newmark NM, Hall WJ (1982) Earthquake spectra and design. Engineering monographs on earthquake criteria, structural design, and strong motion records, vol 3. Earthquake Engineering Research Institute, University of California, Berkeley, CA. 8/5

Ordaz M, Aguilar A, Arboleda J (1999) Program for computing seismic hazard, CRISIS 99-18. UNAM, México

Perkins JB, Harrald J, Jeong D, Chuaqui B (1996) Shaken awake estimates of uninhabitable dwelling units and peak shelter populations in future earthquakes affecting the San Francisco Bay Region. Association of Bay Area Governments, Oakland

PGS-1 (1968) Norma Sismorresistente P.G.S.-1(1968), parte A, Comisión Interministerial de la Presidencia del Gobierno, Decreto 106/1968, del 16 de enero de 1969

Schnabel B, Lysmer J, Seed, HB (1972) Shake. A computer program for earthquake response analysis of horizontally layered sites. College of Engineering, University of California, Berkely. Report No EERC 72-12, p 88

Secanell R, Goula X, Susagna T, Fleta J, Roca A (1998) Analysis of seismic hazard in Catalonia (Spain) through different probabilistic approaches. In: Proceedings of the 11th European conference on earthquake engineering, Ed. Balkema. Paris, France

Secanell R, Goula X, Susagna T, Fleta J, Roca A (2004) Seismic hazard zonation of Catalonia, Spain, integrating uncertainties. J Seismol 8:24-40

Susagna T, Goula X (1999) Catàleg de Sismicitat. Atlas sísmic de catalunya. Institut Cartogràfic de Catalunya, Barcelona, vol 1, 436 pp

Vacareanu R, Lungu D, Aldea A, Arion C (2004) WP7 report seismic risk scenarios handbook. RISK-UE project of the EC: an advanced approach to earthquake risk scenarios with applications to different European towns

Vielma JC, Barbat AH, Oller S (2008) Comportamiento sísmico de edificios de hormigón armado de ductilidad limitada. Hormigón y acero 248:87-101

Wells DL, Coppersmith KL (1994) New empirical relationships among magnitude, rupture length, rupture width, rupture area, and surface displacement. Bull Seismolog Soc Am 84(4):974-1002 